\title{
Seismic analysis of masonry gravity dams using the Discrete Element Method: Implementation and application
}

\author{
EDUARDO M. BRETAS ${ }^{1}$, JOSÉ V. LEMOS ${ }^{2}$, and PAULO B. LOURENÇO ${ }^{3}$ \\ ${ }^{1}$ Department of Infrastructure, Materials and Structures, Northern Research Institute, \\ Narvik, Norway \\ ${ }^{2}$ Department of Concrete Dams, National Laboratory for Civil Engineering, Lisboa, \\ Portugal
}

${ }^{3}$ Institute for Sustainability and Innovation in Structural Engineering, University of Minho, Guimarães, Portugal

\begin{abstract}
Much research in recent years has focused on the seismic analysis of concrete and earthfill dams, and few works have addressed the case of masonry dams. The structural behaviour of masonry dams is controlled essentially by its discontinuous nature, which may induce significant non-linear response during an intense earthquake. In this paper a numerical tool based on the Discrete Element Method is presented, aimed at the static, dynamic and hydromechanical analysis of masonry gravity dams. The use of discontinuous models is mandatory for the study of failure mechanisms involving the masonry discontinuities, the dam-rock interface or the rock mass joints. The Discrete Element Method is able to assemble continuous and discontinuous meshes simultaneously in the same model, providing a versatile tool to consider various assumptions and levels of analysis, ranging from simplified to detailed structural representations. A comprehensive study of the seismic behaviour of Lagoa Comprida Dam, located in Portugal, is presented. Both continuous and discontinuous models were developed to assess the main failure mechanisms, including overstress, partial and global sliding and overturning.
\end{abstract}

\section{Key Words}

Masonry dams, discrete elements, seismic analysis, safety assessment, gravity dams 


\section{Introduction}

The seismic action is a central problem in the safety of different type of structures. In dam engineering, due to the huge consequences of a failure and high potential risk, the dam safety against earthquakes is of great concern. Amongst the consequences of an earthquake, in addition to immediate damage, minor vulnerabilities may arise, leading to future incidents. ICOLD [2001] analysed a set of dams subjected to seismic events, and found that $17 \%$ collapsed or suffered serious damages, $36 \%$ suffered minor or moderated damages and in $47 \%$ of the cases no damages were detected. Rogers dam, located in Nevada, USA, is an example of a masonry dam collapse, because of the Fallon earthquake, in 1954. The cases of Shih-Kang in Taiwan, Koyna in India, Hsinfenkiang in China, Sefid Rud in Iran, Pacoima in USA, Rapel in Chile, Honen-ike in Japan and Blackbrook in UK are well-known examples of collapses or serious damages in concrete dams caused by earthquakes [Léger, 2007].

The seismic analyses of dams generated considerable research interest in the last 50 years with the development of the Finite Element Method as described by Clough and Wilson [1999]. Nowadays the uses of sophisticated models, including dam-waterfoundation interaction effects [Chopra and Wang, 2012] are widespread. More recently, work has been devoted to the seismic assessment of existing dams using progressive analysis methodologies [Bretas et al., 2014a] to overcome the uncertainties of the material properties and the loads. Most of those studies are focused on concrete and earthfill dams, and few works have addressed the case of masonry dams.

Most of the existing masonry dams, both in Europe and America, were built in the second half of the $19^{\text {th }}$ century [Bretas et al., 2012]. Generally, these structures have been subjected to rehabilitation works, and remain in use. Many structural problems of masonry dams result from aging and are different from those that occur in concrete dams. Often, the problems are related to the cohesion loss of masonry due to the chemical and physical effects of the water. In addition, some of these dams present structural vulnerabilities that reflect the knowledge available at the time they were designed, for example, as earthquake resistance is concerned. Today, the operation of these dams represents a relevant challenge for professionals, since structural safety has to be verified according to modern standards and regulations.

The safety assessment of masonry dams using numerical models demands appropriate tools to take into account the discontinuous nature, the non-linear behaviour, and the hydromechanical interaction, resulting from the water seepage within the dam body and the foundation. Equivalent continuum models have been the most common approach in the study of masonry dams, namely in the framework of rehabilitation projects [e.g. Wittke et al., 2003; Bureau et al., 2005]. An important aspect that needs to be examined concerns the representation of the internal structure of the masonry material. The Discrete Element Method (DEM) has proved to be suitable for the masonry dams analysis, because it allows the explicit modelling of the discontinuities. These 
discontinuities may control the structural behaviour of the dam-foundation-reservoir system, especially the non-linear response expected during a strong seismic event.

In this paper a numerical tool based on the DEM is presented for the dynamic analysis of masonry gravity dams. Its application to static and hydromechanical studies was reported in previous works [Bretas et al., 2013; Bretas et al., 2014b]. A brief overall description is provided next, while the extensions required for seismic analysis are covered in detail in subsequent sections. To address the main practical situations and design requirements, the model may include rigid blocks, deformable blocks and continuum FE meshes. Determination of natural frequencies in the elastic range, as well as time domain non-linear dynamic analysis, is feasible. A comprehensive study of the seismic behaviour of Lagoa Comprida Dam, a $28 \mathrm{~m}$ high masonry dam with a length of $1200 \mathrm{~m}$, located in Portugal, was performed. The dam was heightened several times and was subjected to major rehabilitation works. Both continuous and discontinuous models were developed in order to assess the main failure mechanisms, including overstress, partial and global sliding and overturning. Comparison of results obtained with simplified and elaborate models provided useful conclusions about the strengths and drawbacks of each approach.

\section{Seismic analysis of masonry gravity dams}

In many countries, the earthquake load is critical in the design of new dams as well as in the safety assessment of existing dams. Generally, for gravity dams, the permanent sliding along any plane within the dam body, along the interface between the dam and the foundation or along geological discontinuities in the rock foundation, is the main failure mechanism. Nevertheless, the stress field generated by the earthquake is also important, specially the maximum tensile stress, responsible for cracking. A particular case is the RCC (Roller Compacted Concrete) dams, whose quasi-horizontal construction joints are usually potential sliding planes [Wieland and Ahlehagh, 2013]. With less emphasis, concrete cast joints, in dams built with traditional concrete, are also planes to be checked. In other cases, geometry singularities of the dam body, as for example at the crest, the sliding may occur in association with rocking. Those aspects are even more relevant in the case of masonry gravity dams, in which discontinuities are subject to high uplift (pore) pressure due to the water seepage.

For seismic analysis, at least one earthquake with medium probability of occurrence (unusual scenario) and another with low probability of occurrence (extreme scenario) should be analysed. The regulation produced by USACE [1995], for example, recognizes three scenarios where the seismic load is predominant. Two of them involve the Operating Basis Earthquake (unusual scenario), being one of those with the reservoir empty. The third involves the Maximum Credible Earthquake (extreme scenario). The stability is evaluated by means of safety factors, while the stress field generated by the seismic loading is assessed by a performance criteria, which establishes for unusual scenarios, that the dam should present an elastic behaviour; and 
for extreme scenarios, the tensile and the compressive stresses may exceed the material strength in some points, possibly in conjunction with local or global permanent displacements, but without putting at risk the global safety of the dam. The judgement of these criteria varies according to the structure characteristics and local conditions. A different approach is proposed by FERC [2002], because the assessment of the structural safety is done indirectly, considering the stability of the dam after the earthquake. This analysis is made for the normal operating conditions, taking into account the damages induced by the seismic event.

The method applied for dynamic analysis of gravity dams depends on the degree of sophistication required. The combination of different methods can be part of a progressive methodology, bringing benefits to the understanding of the dam behaviour and lower analysis costs. Among the most expedite methods, the pseudo-static analysis considers inertia forces as the product of mass times the ground acceleration. This procedure disregards the amplification effect due to the flexibility of the dam, as well as the oscillatory nature of the seismic load. Another simplified method called pseudodynamic, developed by Chopra [1988], is similar to the pseudo-static seismic analysis except that it recognizes the dynamic amplification of the inertia forces along the height of the dam, by the simplified response spectra method. The dynamic amplification is considered only in the horizontal direction. The dynamic flexibility of the damfoundation is modelled by means of the Young's modulus of the concrete and the rock mass. The oscillatory nature of the inertia forces is not considered, the horizontal and vertical loads are continuously applied. Among the more elaborate methods, those based on the Finite Element method stand out. This procedure assumes that the structural response in the elastic range can be evaluated from the combination of the vibration modes most relevant for the scenario in analysis. This procedure can be implemented with the response spectra or, in alternative, from an acceleration history using the Duhamel integral.

For non-elastic behaviour, either finite element or discrete element models can be used, based on time domain analysis methods. The Discrete Element Method (DEM) has been applied to the analysis of gravity dams mostly in static and hydromechanical studies [e.g. Gimenes and Fernández, 2006; Barla et al., 2004]. In the numerical model presented in this paper, based on the DEM, seismic analysis is carried out by direct integration of the equation of motion for each degree of freedom. The formulation developed includes deformable blocks based on finite elements to allow a good representation of the dam deformability [Bretas et al., 2014b]. It thus allows the determination of natural modes of vibration and frequencies if linear elasticity is assumed, but it is mainly intended for the analysis of structural failure modes, damage and permanent displacements resulting from seismic action. For this purpose, it takes advantage of the ability of DEM models to represent explicitly discontinuities with nonelastic behaviour, either in the dam body, the dam-rock interface, or in the rock mass. The occurrence of separation or sliding along any joint or interface during the seismic 
event, and its effects on structural safety, can therefore be assessed with the present model.

\section{Fundaments of the Discrete Element Method (DEM) model}

The model presented in this paper, based on the DEM [Bretas et al., 2014b; Bretas, 2012], is intended to represent in an integrated manner the masonry dam and the rock foundation as components of a blocky system (Fig. 1a). The DEM approach starts from an initial discontinuity network, which corresponds to a simplified representation of the masonry structure and the rock mass joints, assumed to be preferential paths for fracture propagation. It thus differs from numerical models of fracture propagation in a continuum unaffected by pre-existing discontinuities [e.g. Domaneschi, 2012], or smeared crack formulations based on equivalent continuum models of the dam and rock mass [e.g. Hariri-Ardebili, 2014].

For gravity dams, the standard two-dimensional analysis is conservatively assumed, disregarding the arch effect across the valley. The fundamental element of numerical discretization is the block with three or four edges (faces), which may be rigid or deformable. In case of deformable blocks, each block is assumed here as an isoparametric linear Finite Element with full Gauss integration. Blocks of general shapes may be created by assembling the 3 and 4 node blocks into macroblocks (Fig. 1b). A rigid block has 3 degrees-of-freedom ( 2 translations and 1 rotation), while for deformable blocks, there are 2 (translational) degrees of freedom per node.

The mechanical interaction between two blocks is defined as a numerical contact. All contacts, created in the first iteration, are assumed to be of the type face-to-face. This type of contact is implemented with two sub-contacts (Fig. 1c). It is possible that the face-to-face contact degenerates to a vertex-to-face contact type, if one sub-contact opening is greater than a given tolerance, while the other sub-contact opening remains below that tolerance. The face-to-face contact allows a linear stress distribution, with a trapezoidal shape, and a proper application of the joint constitutive model (Fig. 1d). Thus, the distribution of the contact forces is statically consistent with the diagrams and the bending stiffness is correct. The contact forces are calculated from the integration of the stress diagram established in the contact. The method of integration controls the rotation stiffness of the contact. The point contact model (Fig. 1e), typically used in most DEM codes, is the most rigid, while trapezoidal models used herein provide a better approximation, as shown by comparisons presented in [Bretas et al., 2014b].

Numerically, the time domain calculation involves setting up and integrating the equation of motion for each degree of freedom of the model. The integration of the equation of motion, which is a second order differential equation, is made explicitly, according to the method of the central differences. Static solutions are also obtained with this algorithm, by dynamic relaxation, using scaled masses and artificial damping. Viscous mass-proportional damping is used, with an adaptive scheme that updates the 
damping coefficient step-by-step based on the dominant frequency of the structure from the Rayleigh quotient. The seismic analysis, the flow analysis and the structural strengthening analysis are integrated in the mechanical cycle, sharing the same model data and allowing fully coupled analysis.

Fig. 2 shows the calculation cycle. In the initial stage (Fig. 2, step 1), forces are computed and added to each independent degree of freedom. All the loads type, as dead loads, dynamic loads, hydraulic loads and the use of structural reinforcements, are managed simultaneously and in a consistent arrangement. Next, the equations of motion are established and solved (Fig. 2, step 2). Subsequently, absolute and relative position of all blocks is updated (Fig. 2, step 3) and the verification of active contacts and the attempt to detect new ones take place (Fig. 2, step 4).

For seismic analysis, real masses and damping values have to be employed, and the boundary conditions are modified from the static model, imposing the dynamic load through a velocity or stress history. The analysis also requires other extensions to the standard DEM formulation, to consider aspects, such as: (i) the influence of the reservoir on the dynamic behaviour of the structure, (ii) discretization refinement of the model according to the maximum wave frequency which is propagated through the mesh, (iii) the boundary conditions according to the method of applying the dynamic load and, finally, (iv) the type of damping to be assumed and the numerical issues.

\section{Extension of the DEM model to seismic analysis}

\subsection{Application of seismic loading}

Three different procedures to model dynamic loads and to define boundary conditions were implemented. In the first scheme (Fig. 3a), modelling the foundation as a rigid block, the seismic load is applied as a velocity history. In the second scheme (Fig. 3b), modelling the foundation as a deformable block, a stress history is applied in only one of the directions, either horizontal or vertical, superimposed on a viscous boundary to absorb the reflected waves by the free surface and the structure. The third scheme (Fig. $3 c$ ), adopting a deformable block to model the foundation, allows the input of the dynamic load in two directions simultaneously, using the free-field condition on the lateral boundaries. These procedures may be complementary, corresponding to different levels of analysis. An initial analysis with rigid foundation requires fewer parameters and resources. The results are usually conservative and may be an upper limit, possibly more adequate for a preliminary study. The use of a deformable foundation requires more information about the characteristics of the reservoir-dam-foundation system, but allows for results that are more realistic. The last approach should be used for an advanced phase of analysis, when better knowledge is already established about the structural behaviour of the dam. For all cases, the static analysis of the dam, under the action of permanent loads, precedes the seismic analysis. The loads involved in that 
analysis include the self-weight, the hydrostatic pressure and the uplift pressure. Before changing the boundary conditions and applying the dynamic load, the initial boundary restrictions should be released and the resulting reactions from the static analysis should be added as external forces.

\subsubsection{Model with rigid foundation and application of the dynamic load using a velocity history}

In this procedure the seismic load is applied as a velocity history. The procedure can be adopted when the earthquake is considered in one direction or in two directions. For the horizontal component, the direction $(x)$ is associated with a velocity history, and in the vertical direction $(y)$ the velocity is set null (Fig. 3a). A similar procedure can also be applied when the earthquake has only the vertical component. In the general case, both horizontal and vertical components are applied, with different velocity histories prescribed in each direction.

\subsubsection{Model with deformable foundation and application of the dynamic load using a stress history}

In this case, it becomes unfeasible to introduce the seismic load using a velocity history at the base of the model, because it is necessary to apply, at the same time, a nonreflecting boundary to absorb the waves reflected by the free surface, the foundation and the structure. The viscous boundary formulation proposed by [Lysmer and Kuhlemeyer, 1969] was used. Thus the seismic load is applied through a shear or normal stress history, computed from the velocity history, considering the rock mass elastic properties. Using this methodology, it is possible to apply one of the components of the dynamic load at a time, the horizontal or the vertical component. In the case of a vertically propagating shear wave, shear stresses are applied at the model base, resulting in horizontal displacements, and the lateral boundaries of the foundation are fixed in the vertical direction to ensure that theoretical shear wave conditions (Fig. 3b). At the base of the foundation, a viscous boundary is also applied in the horizontal direction. If a vertical P-wave is considered, then the lateral boundaries of the foundation are restrained in the horizontal direction to ensure that the load is essentially imposed on the vertical direction. In this case, at the base of the foundation, a viscous boundary is applied in the vertical direction. The model is intended to include the case of non-elastic behaviour in the foundation rock mass, for this reason the traditional hypothesis of a massless and an elastic medium are not invoked. The rock mass is represented with its real mass and constitutive model.

The seismic wave propagation through the model is conditioned by the degree of discretization of the dam and foundation. The wavelength for the reference frequency should be equivalent to the width of at least eight elements [Lysmer and Kuhlemeyer, 1969]. For a discontinuous field, for example in case of highly fractured foundations, 
the properties of the discontinuities must be considered to compute the equivalent bulk and shear modulus.

\subsubsection{Model with deformable foundation and application of the dynamic load using a free-field condition}

The third option of seismic load modelling uses a technique known as free-field [Lemos and Cundall, 1999], applied at the lateral boundaries to simulate an infinite lateral extension of the model. A complementary model mesh is computed in parallel with the main model, composed by two columns, one on each side of the foundation, with unitary width, whose height is coincident with the discretization of the foundation. At the base of these columns, the same boundary conditions and dynamic loads of the main model are applied (Fig. 3c). The analysis of the 1D propagation of this input in the vertical direction provides the velocities and stresses for a horizontally infinite medium. The columns are composed by four side elements, with four nodal points, using four Gauss points to integrate the stiffness matrix. Each free-field element is associated with the element of the foundation, which inherits the material and properties.

The columns represent the dynamic behaviour of the free-field, at some distance from the dam. At each time step, the horizontal and shear stresses of the free-field mesh are applied to the main model. In addition, in order to absorb waves reflected from the dam and foundation, viscous dampers are used between the main mesh and free-field. These dampers are applied to the difference in velocities, following the Lysmer and Kulhmeyer 1969 formulation. At each time step, the nodes of the lateral boundaries of the main mesh are applied the following forces by the free-field:

$f_{x}=\left(\sigma_{x x} n-\rho C_{P}\left(v_{x}-v_{x, f f}\right)\right) L$

$f_{y}=\left(\sigma_{x y} n-\rho C_{S}\left(v_{y}-v_{y, f f}\right)\right) L$

where: $\sigma_{x x}$ is the horizontal stress of the free-field element; $\sigma_{x y}$ is the shear stress of the free-field element; $n$ is -1 or 1 for the left and right lateral boundaries; $\rho$ is the density of the rock mass; $C_{S}$ is the propagation velocity of a transversal wave in a continuous medium; $C_{P}$ is the propagation velocity of a longitudinal wave in a continuous medium; $v_{x}$ and $v_{y}$ are the main mesh velocity in the $\mathrm{x}$ - and y-direction; $v_{x, f f}$ is the velocity of the free-field in the $\mathrm{x}$ direction; $v_{y, f f}$ is the velocity of the free-field in the y direction; and $L$ is the influence area of the point.

The main advantage of using free-field compared to previous solutions is the simultaneous application of the vertical and horizontal components of the seismic load. 
Another advantage is the absorption of the reflected wave, incident on the sides of the model, which in the previous case was only possible at the base.

\subsection{Hydrodynamic pressure of the reservoir}

The Westergaard added mass method is employed to represent the dam-reservoir dynamic interaction. Experimental evidence has shown that this solution reproduces reasonably well the decrease of dam natural frequencies caused by the presence of the reservoir [e.g. Scheulen et al., 2010; Kuo, 1982]. Formulations with more precise representation of the fluid-structure interaction, using fluid elements, have been used, mainly, for arch dams, where hydrodynamic effect of the reservoir is more relevant. During an earthquake, the dam is subject to a variation of the water pressure along the upstream. Westergaard [1933] proposed a solution to estimate the pressure diagram, according to the (i) acceleration imposed by the earthquake, (ii) density of the water, (iii) reservoir height, (iv) deformation modulus of water and (v) the fundamental vibration frequency of the structure. The same author also proposed a simplified solution, known as added masses, considering the effect of a water volume that moves with the dam during an earthquake, giving rise to inertial forces. This volume is parabola-shaped and is given by,

$m_{h, i}=\frac{7}{8} \rho_{w} \sqrt{H y_{i}} A_{i}$

where: $m_{h, i}$ is the mass associated to the point $i$ on the horizontal direction; $\rho_{w}$ is the water density; $H$ is the reservoir elevation; $y_{i}$ is the water depth at node $i$ measured from the surface; and $A_{i}$ is the tributary area of the point $i$.

The additional mass obtained is added to the mass of the points that define the upstream face. This formulation has been developed for a dam with vertical upstream face. For its generalization, the formulation must be adjusted according the inclination of the upstream face [Priscu et al., 1985]. In general, the upstream face of gravity dams is moderately inclined, consequently the horizontal component is almost not affected, and the vertical component is reduced, both with small impact on the dynamic behaviour of the structure.

\subsection{Rayleigh damping for DEM dynamic analysis}

For dynamic analysis, Rayleigh damping was adopted, considering the two components, proportional to the mass $(\alpha)$ and proportional to the stiffness $(\beta)$. In cases where both components are not null, the Rayleigh damping is almost constant for a frequency range around the damping curve minimum. The damping selected is adjusted to the dominant frequencies according the problem under analysis. For the natural frequencies 
assessment, the method of vector reverse iteration was adopted, in combination with the orthogonalization method of Gram-Schmidt.

The damping component proportional to the mass is taken into account in the equations of motion. The stiffness-proportional component is considered by adding damping forces to the normal and tangential contact forces, and to the nodal forces of each finite element. The Rayleigh damping proportional to the stiffness should only be applied in the contact forces when the joint presents an elastic behaviour, since the corrections by the constitutive model already involve some energy dissipation. Thus, if the contact exceeds the maximum tension or compression, the damping proportional to the stiffness is not considered in any direction. If the contact remains within the limits of normal stress, but does not respect the constitutive model in the tangential direction, the damping component is only applied in the normal direction.

For numerical stability of the explicit algorithm, the time step should be reduced when damping proportional to the stiffness is used. According to Belytschko [1983], the adjusted time step is given by,

$\Delta t_{d y n}=\Delta t_{s t a}\left(\sqrt{1+\lambda^{2}}-\lambda\right)$

where: $\Delta t_{d y n}$ is the dynamic time step considering the damping proportional to the stiffness; $\Delta t_{s t a}$ is the static (reference) time step; and $\lambda$ is the relative damping coefficient for the maximum frequency.

Although reducing $\Delta t$ may be a significant disadvantage in terms of computational performance, the use of the stiffness-proportional component in nonlinear analysis is important, namely in failure scenarios of gravity dams, especially for the sliding failure mechanism. In this case, for example, the trend is for a gradual failure and reduction of the natural frequency of the structure. The damping proportional to the stiffness decreases, when the damping proportional to the mass increases [Hall, 2006]. In addition, the damping proportional to the stiffness seems to be most appropriate as it is applied directly to the dam-foundation interface, while the damping proportional to the mass is applied to the entire structure.

\subsection{Example of validation}

The example of validation [Bretas, 2012] is based on the report of Chopra and Zhang [1991] aimed at the study of the base sliding response of concrete gravity dams under earthquakes. These authors employed analytical procedures considering hydrodynamic effects for the case of a gravity dam, $400 \mathrm{ft}$ (ca. $121.9 \mathrm{~m}$ ) high, assuming the dam flexibility by the contribution of only the fundamental mode of vibration. The DEM model used a rigid foundation, with seismic loading applied at the model by means of a 
shear velocity history, as explained in the previous sections. The excitation was the S69E component of the Taft (1952) ground motion with peak acceleration amplified to 0.5g. In Fig. 4 is plotted the response history of earthquake-induced sliding on a purely frictional horizontal planar surface of rock. Comparing with the Chopra and Zhang example, the results show that the total permanent sliding are in the same order-ofmagnitude, being $0.38 \mathrm{~m}$ for the example of Chopra and Zhang, and $0.39 \mathrm{~m}$ for the DEM model. The displacement history is also comparable. The differences could be explained by the method employed by Chopra and Zhang to represent the deformation of the dam, using only the fundamental mode of vibration, ignoring the higher modes.

\section{The case study of Lagoa Comprida dam}

Lagoa Comprida dam is a masonry gravity dam, located in Portugal, in Seia municipality, with an M-shape plan, $28 \mathrm{~m}$ high above the foundation, crest elevation of $1600 \mathrm{~m}$, and $1200 \mathrm{~m}$ length. The construction of Lagoa Comprida dam began in 1912, reaching $6 \mathrm{~m}$ height in 1914. Subsequently, the structure was heightened several times, until the last heightening carried out during a major rehabilitation work, between 1964 and early 1967, when the height reached $28 \mathrm{~m}$. This reinforcement works of Lagoa Comprida dam comprised the construction of a concrete slab over the upstream face, anchored to the dam and adequately drained. These works also included a grouting treatment aimed at the consolidation of the dam body and reduction of the foundation permeability, and the execution of a drainage system in the foundation (Fig. 5). The thickness of the concrete slab varies between $0.5 \mathrm{~m}$ near the crest and $0.7 \mathrm{~m}$ near the foundation. Above the old crest of the dam $(1597 \mathrm{~m})$ a new concrete block was erected, connecting to the concrete curtain, with a section of $2.0 \mathrm{~m}$ by $3.0 \mathrm{~m}$ [Silveira and Ramos, 1994].

A comprehensive study of the seismic behaviour of Lagoa Comprida dam was carried out [Bretas, 2012]. Four models were developed (Fig. 6), using different discretization techniques and dynamic load modelling. In the first model (model R-R) both dam and foundation are assumed rigid, corresponding to a simple 2-block system. The dynamic input is applied to the foundation block as a velocity history. In the second model (model D-R), the dam is modelled using deformable blocks while the foundation is a rigid block. The way that the dynamic load is applied is similar to the model R-R. In the third model (model D-D) both dam and foundation are modelled using deformable blocks. The dynamic load is applied as a stress history at the foundation base. The fourth model (model F-F) is also modelled with deformable blocks, but using the lateral free-field boundary condition.

Based on these models, a set of analyses was developed, summarized in Table 1. For the static loads, the stress on the dam-foundation interface was examined, using a rigid foundation (model D-R-1), and a deformable foundation (model D-D-1). A series of analyses for the sliding scenario along the dam-rock interface were carried out, considering only the horizontal component of the earthquake. In the first case, the dam 
and the foundation were modelled with rigid blocks (model R-R-1). For the dam modelled with deformable blocks, models with rigid foundation (model D-R-2) and with deformable foundation (model D-D-2) were analysed.

For the earthquake, which induced higher sliding, the stress envelope of the upstream face was estimated (model D-D-3). For the same load case, the stress history at the upstream heel and at the downstream toe was analysed (model D-D-4). The model D-D5 was developed in order to assess the amplification effect owing to the dam flexibility, between the base and the crest, in terms of the horizontal velocity and displacement, and computing the relative displacement. Furthermore, a parametric study was subsequently conducted regarding to different types of damping (model D-D-6), i.e., massproportional, stiffness-proportional, and both components, all with $5 \%$ of critical damping at the fundamental frequency. Those analyses were repeated for the scenario of full uplift on the base of the dam, and for the load case defined by the design seismic load, magnified by a factor of two.

The analysis considering the seismic load in the horizontal and vertical directions simultaneously was also undertaken (model F-F-1). Six combinations, using accelerograms 1 and 5 (artificially generated according to the spectrum provided in the applicable code) which produced the largest displacements in model D-D-2, were considered. Based on model F-F-1, the stability of the concrete block located at the top of the dam was also discussed (model F-F-2). Finally, a detailed model of the dam, representing the masonry laid out in horizontal layers, and considering the construction joint arising from a heightening that occurred in 1934 was analysed (model F-F-3), to examine the failure through the masonry discontinuities. The meshes representing the dam are showed in detail in Fig. 7.

\subsection{Main input data required to carry out the seismic analysis}

In the models D-R, D-D and F-F the dam body is modelled as a continuous finite element mesh (i.e., a single macroblock). In those cases, the density of the material is $2500 \mathrm{~kg} / \mathrm{m}^{3}$, Poisson's ratio is 0.2 and the Young's modulus is $11 \mathrm{GPa}$. In the models D$\mathrm{D}$ and F-F the foundation is also modelled as a macroblock. The Young's modulus for the rock mass is $20 \mathrm{GPa}$, while the rest of the values are assumed the same as before. Those values were obtained by back-analysis from the monitoring system of Lagoa Comprida dam [Bretas, 2012], and might include some 3D effects not considered in the 2D model. For the rigid blocks, both dam and foundation, the same density is adopted. An inelastic joint is assumed on the dam-foundation interface, with null tensile strength, null cohesion and a friction angle of $45^{\circ}$. For this discontinuity, a normal stiffness of 20 $\mathrm{GPa} / \mathrm{m}$, and a tangential stiffness of $6.7 \mathrm{GPa} / \mathrm{m}$ were adopted.

The load combination corresponds to the normal operating scenario of the dam, in addition to the maximum expected earthquake, for the region where the dam is located. The hydrostatic pressure was defined for a reservoir elevation at the crest, $28 \mathrm{~m}$ above 
the foundation plan, as well as the hydrodynamic pressure. The uplift pressure corresponds to the conventional triangular diagram, with a reduction of $2 / 3$ upstream due the drainage system, whose gallery is located at the dam heel.

The Rayleigh damping was taken as $5 \%$ of critical damping, as suggested by the USBR [1987], centred to the frequency of $6 \mathrm{~Hz}$, which approximately corresponds to the fundamental frequency of the structure. The first four eigenmodes are shown in Fig. 8. Five accelerograms are selected, with peak acceleration of $0.15 \mathrm{~g}$ and full duration of 20 s, with intense phase of 15s (Fig. 9), generated artificially from the EC8 spectrum for a short-distance earthquake scenario. This value corresponds to the maximum design earthquake for dams in this region.

First, the dead loads are applied, i.e. the self-weight, the hydrostatic pressure and, finally, the uplift. The seismic analysis starts from the model after the static analysis, releasing the fixed points of the boundaries, and applying the added mass due the hydrodynamic pressure of water.

\subsection{Model R-R (Rigid dam - Rigid foundation)}

The first analysis (model R-R-1) was performed using rigid blocks for both foundation and dam. In this case, the results show a great variability according to the deformability given to the dam-foundation joint. In the case of Lagoa Comprida dam, after the application of earthquake number 5 , the dam has a displacement of $10 \mathrm{~mm}$ when a normal stiffness of $2 \mathrm{GPa} / \mathrm{m}$ is assumed, $0.1 \mathrm{~mm}$ for $20 \mathrm{GPa} / \mathrm{m}$ stiffness and $0.001 \mathrm{~mm}$ for $200 \mathrm{GPa} / \mathrm{m}$ stiffness. This is a consequence of the different natural frequencies of the dam rigid block, supported by two contact springs, which drastically change the dynamic response. This model is therefore oversimplified, and is not a reliable tool to examine the seismic sliding behaviour.

\subsection{Model D-R (Deformable dam - Rigid foundation)}

\subsubsection{Analysis D-R-1: Stress on the interface (static)}

Fig. 10a shows the normal and tangential stress along the dam-foundation interface, after the application of all static loads, including self-weight, hydrostatic pressure and uplift, for the model with rigid foundation and deformable dam. In this case, a shear failure occurs in the first $6 \mathrm{~m}$ of the base, near the heel of the dam, where the two stress diagrams, shear and normal, are superimposed. This implies, based on the MohrCoulomb criterion with a friction angle of 45 degrees, null tensile stress and null cohesion, that the tangential stress is equivalent to the tangential strength capacity. A failure by tension at the first contact upstream is observed, since the normal stress is zero. 


\subsubsection{Analysis D-R-2: Permanent displacement}

The permanent displacements are assessed qualitatively looking at the horizontal displacement history at the dam heel, on the upstream face. The displacement is computed as the difference between the initial displacement, from the static calculation, and the final displacement, after the earthquake. The results obtained for the five earthquakes, for the model with rigid foundation, are shown in Fig. 11, and display a typical behaviour, with short episodes in which sliding accumulates rapidly. The dam presents the larger displacement for earthquake number 4 , about $14.4 \mathrm{~mm}$.

\subsection{Model D-D (Deformable dam - Deformable foundation)}

\subsubsection{Analysis D-D-1: Stress on the interface (static)}

Fig. 10b shows the normal and tangential stress on the dam-foundation interface, after the application of all static loads, including self-weight, hydrostatic pressure and uplift, for the model with deformable foundation. The results show a failure by shear in the first $3 \mathrm{~m}$ of the base, along the heel of the dam. No failure by tension is detected. Comparing the models with deformable and rigid foundation (D-R-1), in the latter model the failure is more extensive, implying less resistance against the seismic load. The inclusion of the foundation deformability leads to a better representation of the interfaces stresses, with the largest normal stresses reached downstream.

\subsubsection{Analysis D-D-2: Permanent displacement}

The results obtained from the five earthquakes, for the model with deformable foundation, are shown in Fig. 12a. The maximum sliding, about $3.6 \mathrm{~mm}$, is obtained from accelerogram 5. Fig. 12b compares the sliding history of the dam heel and the dam toe, for earthquake number 5 . The analysis of those results shows that the sliding is mainly a global movement. The portion due to the horizontal deformation of the structure is reduced. Comparing with the model with rigid foundation (D-R-2), the present model gives less sliding. For example for earthquake 5, the sliding was about 3 times larger, approximately $10.6 \mathrm{~mm}$ in Fig. 11. The model with deformable foundation allows a more rigorous stress diagram along the interface. In addition, the seismic input is represented more realistically as an upward moving wave, instead of forcing the same history at all points. This has a clear effect on the sliding behaviour.

\subsubsection{Analysis D-D-3: Stress at the upstream face (dynamic)}

Fig. 13 shows the minimum and maximum vertical stresses peaks in the upstream face (model with the deformable foundation) for the five earthquakes. The maximum compressive stress is equal to $-0.95 \mathrm{MPa}$, and takes place at a height of $16 \mathrm{~m}$ above the foundation; the maximum tensile stress is $+0.45 \mathrm{MPa}$, at $20 \mathrm{~m}$ height. Both cases arise 
for accelerogram 2. For this same earthquake, the calculation was repeated, but now considering an elastic joint at the dam-foundation interface. There is a general reduction of compressive stress, the minimum is $-0.72 \mathrm{MPa}$ ( $4 \mathrm{~m}$ height). In contrast, the peak of tension is higher, $+0.55 \mathrm{MPa}$ at $20 \mathrm{~m}$ above the foundation.

\subsubsection{Analysis D-D-4: Stress at the interface (dynamic)}

For the model with deformable foundation, considering the earthquake number five, Fig. 14a represents the vertical stress history at the dam-rock interface at the dam heel. The dam loses the contact with the foundation for many short periods. At these instants, the stress is zero, since the joint does not withstand tensile stress. The highest compressive stress is $-0.92 \mathrm{MPa}$, at the time $8.07 \mathrm{~s}$. Fig. 14b represents the vertical stress history at the dam toe (downstream). In this zone, the stress remains in compression and the minimum stress is $-1.03 \mathrm{MPa}$, at time $8.20 \mathrm{~s}$.

\subsubsection{Model D-D-5: Amplification effect of the seismic load}

For earthquake number 5, Fig. 15 represents horizontal velocity histories, measured at the base and crest of the dam. The histories are correlated, but the velocities measured at the top are amplified. The horizontal displacement histories at these 2 points have a similar evolution, with a maximum difference of about $7 \mathrm{~mm}$. As a reference, the horizontal displacement of the dam crest, due the hydrostatic pressure, is about $4 \mathrm{~mm}$.

\subsubsection{Model D-D-6: Permanent displacement. Effect of damping and uplift pressure}

Fig. 16 represents the sliding due the earthquake number 5 for the model with deformable foundation, comparing the results for 5\% Rayleigh damping centred at a frequency of $6 \mathrm{~Hz}$, considering 3 cases: proportional to the mass, proportional to the stiffness and proportional to the mass and stiffness. The highest permanent sliding of $4.4 \mathrm{~mm}$ is reached for the Rayleigh damping proportional to the stiffness, but the differences between the three cases are within a $20 \%$ difference. The lowest permanent sliding of $3.4 \mathrm{~mm}$ occurs for the full Rayleigh damping. To assess the effect of the input magnitude, similar calculations were carried out with earthquake number 5 multiplied by a factor of 2 , with a peak acceleration of $0.3 \mathrm{~g}$. The values of sliding for the three damping options are even closer. However, the permanent sliding was multiplied by approximately 10 times, from 4-5 $\mathrm{mm}$ to $45-55 \mathrm{~mm}$ [Bretas, 2012].

The seismic analysis was again repeated for earthquake number 5 and model with deformable foundation, but now considering the scenario of full uplift, without the reduction of $2 / 3$ at the drains. This analysis simulates the loss of efficiency of the drainage system, as in case of clogged drains. A permanent sliding of approximately $154 \mathrm{~mm}$ is achieved, in contrast with the value obtained for the drained case, about 3.6 $\mathrm{mm}$, which shows the great importance of the drainage system for the seismic safety. 
The 3 cases of Rayleigh damping were also considered. The highest sliding was registered for the model with the damping proportional to the mass and the smaller is for the model with the damping proportional to the stiffness, with a reasonable difference (about 30\%).

The applicability of the type of Rayleigh damping seem to be dependent on many simultaneous factors, such as the dynamic characteristics of the structure, characteristics and magnitude of the dynamic load, the reference frequency used to centre the damping, and the consideration of nonlinear behaviour during the analysis. The use of Rayleigh damping proportional to the stiffness, for numerical stability reasons, requires a drastic reduction of the time step. Therefore, the number of calculation steps, in many cases, is very high. Table 2 shows the value of the time step, the coefficients of the viscous damping proportional to mass and stiffness, and the number of calculation steps that were required according to the damping type. As the processing time of each calculation cycle is similar for all three hypotheses, the time required to process a model with damping proportional to the mass is about 20 times faster than the case with the damping proportional to the mass and stiffness, and about 40 times faster than the use of damping proportional to the stiffness. In this example, the advisable choice seems to be the damping proportional to the mass, as the model shows relatively close results for all three cases, keeping a reasonable computational performance.

\subsection{Model F-F (Free-field boundary conditions)}

\subsubsection{Analysis F-F-1: Permanent displacement}

The last analysis of global sliding corresponds to the simultaneous application of the horizontal and vertical components of the earthquake, which is necessary to use a freefield condition. This model is similar to the model with deformable foundation, except for the dynamic lateral boundary conditions. A set of load combinations was created, using the earthquakes numbers 1 and 5, which had induced the largest response in Fig. $12 \mathrm{a}$.

The analysis was carried for $\mathrm{H}_{1}+2 / 3 \mathrm{~V}_{5}$ (earthquake number 1 in horizontal direction and earthquake number 5 in vertical direction reduced by a factor of $2 / 3$ ), $\mathrm{H}_{1}-2 / 3 \mathrm{~V}_{5}$ (the same as above, but the earthquake number 5 is applied with negative sign), $\mathrm{H}_{5}+2 / 3 \mathrm{~V}_{1}$, $\mathrm{H}_{5}-2 / 3 \mathrm{~V}_{1}$ and, finally, $\mathrm{H}_{5}+2 / 3 \mathrm{~V}_{5}$ and $\mathrm{H}_{5}-2 / 3 \mathrm{~V}_{5}$. The reduction of $2 / 3$ of the vertical component is a common practice in the design of dams. In the latter two cases, the use of the same accelerogram for the horizontal and vertical components is an unusual procedure.

Based on the results shown in Fig. 17, the highest permanent sliding is reached, as expected, for the combinations $\mathrm{H}_{5}+2 / 3 \mathrm{~V}_{5}$ and $\mathrm{H}_{5}-2 / 3 \mathrm{~V}_{5}$, which are correlated inputs. Compared to the deformable foundation model (model D-D-2), only with the shear component, the maximum permanent sliding is increased by about $60 \%$, owing to the 
vertical component. In at least one case, the combination $\mathrm{H}_{1}+2 / 3 \mathrm{~V}_{5}$, the permanent sliding is lower than the permanent sliding obtained with only the horizontal component of the earthquake number 1 (Fig. 12a). Considering only uncorrelated accelerograms, combinations of accelerograms 1 and 5, the maximum permanent sliding is increased about $40 \%$.

\subsubsection{Analysis F-F-2: Rocking of the concrete block on the crest}

The stability of the concrete block $\left(2.0 \times 3.0 \mathrm{~m}^{2}\right)$ constructed on the crest of the dam is also checked. An unfavourable hypothesis was assumed, with a nonlinear joint between the block and the dam, with null tensile strength and cohesion. Again, a friction angle of $45^{\circ}$ was adopted. The analysis was performed for the model with free-field condition, taking into account the load $\mathrm{H}_{5}+2 / 3 \mathrm{~V}_{5}$. The results indicate a permanent sliding of about $5 \mathrm{~cm}$ (Fig. 18a). The sliding displacements measured upstream and downstream are almost identical. Therefore, the block presents a rigid body motion. The effect of rocking is reduced, with a maximum rotation of $0.04^{\circ}$ in the forward direction (counter clockwise) (Fig. 18b), is observed. Although reduced, it is possible to correlate the effect of rocking and the displacement history.

\subsubsection{Model F-F-3: Discontinuous model of the dam body}

A more detailed model of the dam was undertaken, which represents the masonry laid out in horizontal layers (Fig. 19). The joint resulting from the heightening of 1934 (15 $\mathrm{m}$ high) was modelled explicitly. Three different materials were considered to model the concrete, the masonry and the rock mass. For all materials, density is $2500 \mathrm{~kg} / \mathrm{m}^{3}$ and Poisson's ratio is 0.2. The Young's modulus varies depending on the material type, being $30 \mathrm{GPa}$ for the concrete, $11 \mathrm{GPa}$ for the masonry and $20 \mathrm{GPa}$ for rock mass. For all joints, $20 \mathrm{GPa} / \mathrm{m}$ for the normal stiffness, $6.7 \mathrm{GPa} / \mathrm{m}$ for the tangential stiffness, 0.3 $\mathrm{MPa}$ for the tensile strength, $0.15 \mathrm{MPa}$ for the cohesion, and $35^{\circ}$ for the friction angle, were adopted. For the heightening joint, the tensile strength and cohesion are null. It was assumed that, during the earthquake, the concrete slab in the upstream face is not effective.

The earthquake is applied with the free-field condition. Four combinations of earthquakes from 1 to 5 were used, including combinations $\mathrm{H}_{1}+2 / 3 \mathrm{~V}_{5}, \mathrm{H}_{1}-2 / 3 \mathrm{~V}_{5}$, $\mathrm{H}_{5}+2 / 3 \mathrm{~V}_{1}$ and $\mathrm{H}_{5}-2 / 3 \mathrm{~V}_{1}$, as previously described. The largest permanent sliding takes place at the dam-foundation joint (elevation $1572 \mathrm{~m}$ ) and in the masonry joint at elevation $1592 \mathrm{~m}$. This masonry joint coincides with the base of the crest, where the section geometry changes. Fig. 20 shows the sliding history at elevation $1572 \mathrm{~m}$ (dam base) and $1592 \mathrm{~m}$ (below crest) for the four combinations. Sliding histories in both joints are similar. In two cases, the permanent sliding in elevation $1592 \mathrm{~m}$ is greater than the sliding registered at the foundation. In Fig. 20 it is also possible to observe the joint opening history at elevation $1592 \mathrm{~m}$. A strong connection between the opening and 
the sliding episodes on the joint may be observed. The heightening joint seems to have no influence on the dynamic response of the dam.

The post-earthquake safety was checked using the same model. The purpose is to determine a global sliding safety factor, through the dam-foundation interface, after the seismic analysis, i.e. taking into account the cracks and permanent displacements resulting from the application of the earthquake (Fig. 21). Thus, the internal pressure due to water infiltration through the dam was considered, by means of a full coupled hydraulic calculation [Bretas et al., 2013]. The loads correspond to the normal operating scenario, i.e. normal headwater and uplift. The safety factor is determined by progressively reducing the joint strength properties, until failure takes place. The safety factor of 1.75 is obtained, fulfilling the Portuguese regulation of dam design [NPB, 2002], that states a limit of 1.5 .

\subsection{Discussion of the main results}

Three different procedures to carry out the seismic analysis of gravity dams have been presented. For the sliding scenario of the dam along the dam-foundation interface, the assumption of a rigid foundation is the most unfavourable procedure. This can be partly explained by the initial stress state that is established in the dam-foundation interface after the application of the dead-loads, i.e. the self-weight, the hydrostatic pressure and the uplift. The use of free-field is important because it allows the application of the two components of the earthquake, horizontal and vertical, simultaneously. In the example, the model with free-field led to the largest permanent sliding, but the results are sensitive to the accelerogram combination. Even for earthquakes with identical characteristics, the value of the sliding has a great variability between different accelerograms with the same spectrum. Therefore, it is necessary to carry out a large number of analyses, typically three to seven, as recommended by EC8 [2003], preferably including also recorded accelerograms.

Following the seismic analysis obtained from model D-D-3, the maximum stress in the upstream face was determined according to two different scenarios: nonlinear and an elastic dam-foundation joint. The elastic joint increases the maximum tensile peak and, in contrast, reduces the maximum compression peak. Therefore this type of analysis, considering the cases of elastic and inelastic interfaces, is an advisable solution, since the maximum tensile peak is usually the main concern, while compressive stress are usually well below the upper limit of the material strength. The range of stress variation in the dam for different accelerograms is small compared to the range of values of total sliding.

Based on the models developed in this work, a general conclusion about the most suitable Rayleigh damping type cannot be enunciated. Apparently, in nonlinear analyses, the damping proportional to the stiffness leads the largest permanent sliding. Nevertheless, for the same model, the difference between the results of the three 
different type of damping is moderate, similar to the difference found when different accelerograms with the same peak acceleration are used. The problem may be related to the dynamic behaviour of the structure during the earthquake, as the frequency that is preferentially excited by the earthquake changes, and the actual damping may be higher or lower than expected.

The concrete block located at the top of the dam, after the earthquake, has a relative sliding of about $5 \mathrm{~cm}$. This damage probably does not affect the global safety of the structure. The discontinuous model (F-F-3) is essential for the full understanding of the seismic behaviour of Lagoa Comprida Dam. The results showed that, in two cases, the permanent displacement at elevation $1592 \mathrm{~m}$ is larger than the permanent displacement at elevation $1572 \mathrm{~m}$, at the dam base.

Finally, the role of the drainage effectiveness on the seismic behaviour and safety of gravity dams should be stressed. The uplift is similar to a phenomenon of self-weight reduction. This is crucial in the case of gravity dams, because it is the self-weight that withstands the hydrostatic pressure of the reservoir. The installation, maintenance and sometimes the reinforcement of the existing drainage systems are mandatory measures.

\section{Conclusions}

In dam engineering, due to the high potential risk, the safety against earthquakes is a great concern, but it has not been the subject of much research for masonry dams. Today, the operation of these older dams represents a relevant challenge for the professionals, since the structural safety has to be guaranteed according to modern regulations. The choice of representation of masonry dams should be based on the objectives of the analysis. The proposed DEM tool is intended to support various degrees of modelling complexity required in practical applications, as it allows both rigid and deformable blocks, as well as macroblocks with general FE meshes. Elastic analysis to characterize dynamic properties or the response to low level seismic events may be performed with the present model, employed as an equivalent continuum. The global stability problem is a typical case in which a continuous model of the dam fits well, with only the sliding surface represented as a discontinuity. For this purpose, the present model provides a better approximation than simplified techniques that assume the gravity dam to behave as a single rigid body. Failure mechanisms involving the masonry discontinuities, or the rock mass joints, are clear examples in which the use of a blocky system as the one proposed here is mandatory. The ability to assess the possibility of sliding or overturning of blocks near the dam crest during the earthquake has a great practical interest, particularly for older dams in which horizontal cracks or weaker interface may already be present.

The comprehensive study of the seismic behaviour of Lagoa Comprida Dam allowed a comparison of the performance of the various types of model. This study showed that oversimplified models using only two rigid blocks are not adequate to study the sliding 
behaviour under seismic action. The dam dynamic response always needs to be properly reproduced, by means of its discretization into finite elements. In these analyses, the representation of the rock mass deformability provides a more accurate stress distribution on the dam-foundation interface, and therefore of its nonlinear behaviour. The use of free-field boundary conditions also improves the representation of the dynamic behaviour of the rock mass under general seismic actions. The significant variability in sliding displacements resulting from the numerical simulations requires that analyses with multiple earthquake records be performed to obtain meaningful estimates.

The known sensitivity of dam foundations to water pressures and drainage conditions was highlighted, as well as the strong effect that increasing ground acceleration has on sliding movements. The parametric studies involving the effects of damping showed that while including the stiffness-proportional component of Rayleigh damping is advisable, it imposes a high computational cost in explicit time domain analysis. In this study, the results with only the mass-proportional component provided adequate results. However, this cannot be taken as a general conclusion, and for each structure, a preliminary comparison of the two options is advisable.

The proposed model has the capacity to handle complex types of masonry's internal structure, considering its irregular nature, for example, by means of Voronoi polygons or other block geometries. This is an important field, in which further research is welcome, so that more accurate safety estimates may be obtained, avoiding over conservative assumptions.

\section{Acknowledgement}

Permission by EDP - Energias de Portugal, to present the dam modelling results is gratefully acknowledged.

\section{References}

Barla, G., Bonini, M. and Cammarata, G. [2004] "Stress and seepage analyses for a gravity dam on a jointed granitic rock mass," Proc. of the 1st International UDEC/3DEC Symposium, Bochum, pp 263-268.

Belytschko, T. [1983] "An overview of semi discretization and time integration procedures," in Computational methods for transient analysis, Elsevier Science Publishers B.V., Amsterdam, pp 1-65.

Bretas, E.M. [2012] "Development of a Discrete Element Model for Masonry Gravity Dams Analysis," Ph.D. thesis, University of Minho (in Portuguese). 
Bretas, E.M., Lemos, J.V. and Lourenço, P.B. [2012] "Masonry dams: Analysis of the historical profiles of Sazilly, Delocre, and Rankine," International Journal of Architectural Heritage, 6(1):19-45.

Bretas, E.M., Lemos, J.V. and Lourenço, P.B. [2013] "Hydromechanical analysis in masonry gravity dams and their foundations," Rock Mechanics Rock Engineering, 46(2):327-339.

Bretas, E.M., Batista, A.L., Lemos, J.V. and Léger, P. [2014a] "Seismic analysis of gravity dams: a comparative study using a progressive methodology," Proc. of the EURODYN 2014 - 9th International Conference on Structural Dynamics, Oporto.

Bretas, E.M., Lemos, J.V. and Lourenço, P.B. [2014b] "A DEM based tool for the safety analysis of masonry gravity dams," Engineering Structures, 59(Feb):248-260.

Bureau, G., Keller, T.O. and McClelland, S.W. [2005] "Nonlinear seismic analysis of Sweetwater main Dam," Proc. of the 25th USSD Annual Meeting and Conference, Salt Lake City.

Chopra, A.K. [1988] "Earthquake response analysis of concrete dams," in Advanced Dam Engineering for Design, Construction and Rehabilitation, Springer US, pp 416465.

Chopra, A.K. and Zhang, L. [1991] Base sliding response of concrete gravity dams to earthquakes, UCB/EERC-91/05, Earthquake Engineering Research Center, University of California, Berkeley.

Chopra, A.K. and Wang, J. [2012] "Comparison of Recorded and Computed Earthquake Response of Arch Dams," Proc. of the 15th World Conference on Earthquake Engineering, Lisbon.

Clough, R.W. and Wilson, E.L. [1999] "Early finite element research at Berkeley," Proc. of the Fifth U.S. National Conference on Computational Mechanics, Boulder.

Domaneschi, M. [2012] "Experimental and numerical study of standard impact tests on polypropylene pipes with brittle behaviour," J Engineering Manufacture, 226(12):20352046.

EC8 (Eurocode 8) [2003] Design of structures for earthquake resistance - Part 1: General rules, seismic actions and rules for buildings.

FERC (Federal Energy Regulatory Commission) [2002] Engineering guidelines for the evaluation of hydropower projects, Chapter 3 - Gravity dams.

Gimenes, E. and Fernández, G. [2006] "Hydromechanical analysis of flow behaviour in concrete gravity dam foundations," Canadian Geotechnical Journal, 43(3):244-259. 
Hall, J.V. [2006] "Problems encountered from the use (or misuse) of Rayleigh damping," Earthquake engineering and structural dynamics, 35(5): 525-545.

Hariri-Ardebili, M.A. [2014] "Impact of foundation nonlinearity on the crack propagation of high concrete dams," Soil Mechanics and Foundation Engineering, 51(2):72-82.

ICOLD (International Commission on Large Dams) [2001] Bulletin 120 - Design features of dams to resist seismic ground motion, Paris.

Kuo, J.S.H. [1982] "Fluid-structure interactions: added mass computations for incompressible fluid," UCB/EERC-82/09, Earthquake Engineering Research Center, University of California, Berkeley.

Léger, P. [2007] "Reducing the Earthquake Induced Damage and Risk in Monumental Structures: Experience at École Polytechnique de Montréal for Large Concrete Dams," Proc. of the Extreme Man-Made and Natural Hazards in Dynamics of Structures, NATO Advanced Research Workshop on Extreme Man-Made and Natural Hazards in Dynamics of Structures, Opatija, pp 285-310.

Lemos, J.V. and Cundall, P.A. [1999] "Earthquake analysis of concrete gravity dams on jointed rock foundations," in Distinct element modelling in geomechanics, A.A. Balkema, pp 117-143.

Lysmer, J. and Kuhlemeyer, R.L. [1969] "Finite dynamic model for infinite media," Journal of the Engineering Mechanics Division, pp 859-877.

NPB (Design Standards of Dams) [2002] Portaria N. ${ }^{\circ}$ 846/93, Diário da República, Lisboa (in Portuguese).

Priscu, R., Popovici, A., Stematiu, D. and Stere, C. [1985] Earthquake engineering for large dams, John Wiley \& Sons.

Scheulen, F., Von Gersdorff, N., Duron, Z. and Knarr, M. [2010] "Numerical model validation for large concrete gravity dams," Proc. of the 30th USSD Annual Meeting and Conference, Sacramento.

Silveira, A.F. and Ramos, J.M. [1994] "Strengthening and raising of Lagoa Comprida dam,” XVIII ICOLD Congress, Durban.

USACE (United States Army Corps of Engineers) [1995] Gravity dam design.

USBR (United States Bureau of Reclamation) [1987] Design of small dams, Denver.

Westergaard, H.M. [1933] "Water pressure on dams during earthquakes," Transactions of ASCE, 98:418-433. 
Wieland, M. and Ahlehagh, S. [2013] "Dynamic stability analysis of a gravity dam subjected to the safety evaluation earthquake," Proc. of the 9th ICOLD European Club Symposium, Venice.

Wittke, W., Schröder, D. and Polczyk, H. [2003] "Upgrading the stability of three masonry dams in different ways," Proc. of the ISRM 2003 - Technology roadmap for rock mechanics, South African Institute of Mining and Metallurgy, pp 1321-1327. 


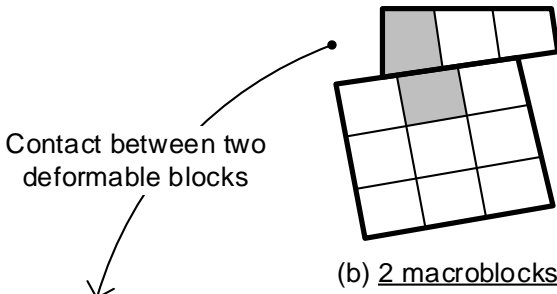

(c)

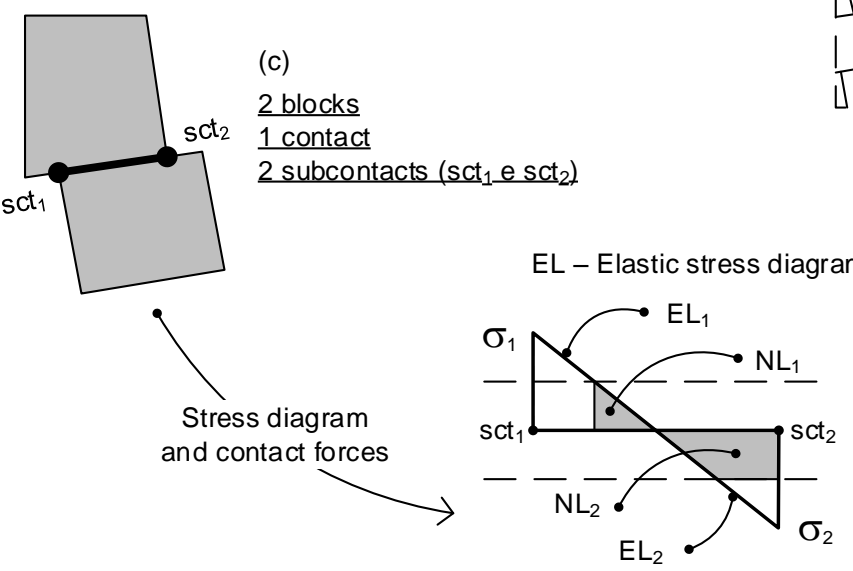

(d) Irapezoidal stress diagram (face-to-face contact)

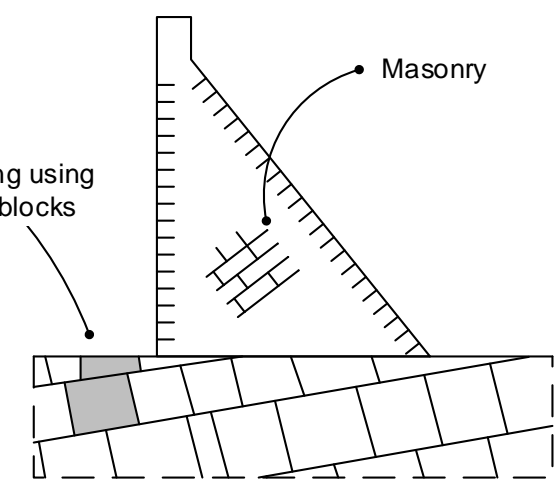

(a) Discontinuites in the dam body and in the rock mass foundation

Fig. 1 - Modelling aspects of the Discrete Element Method (DEM) 


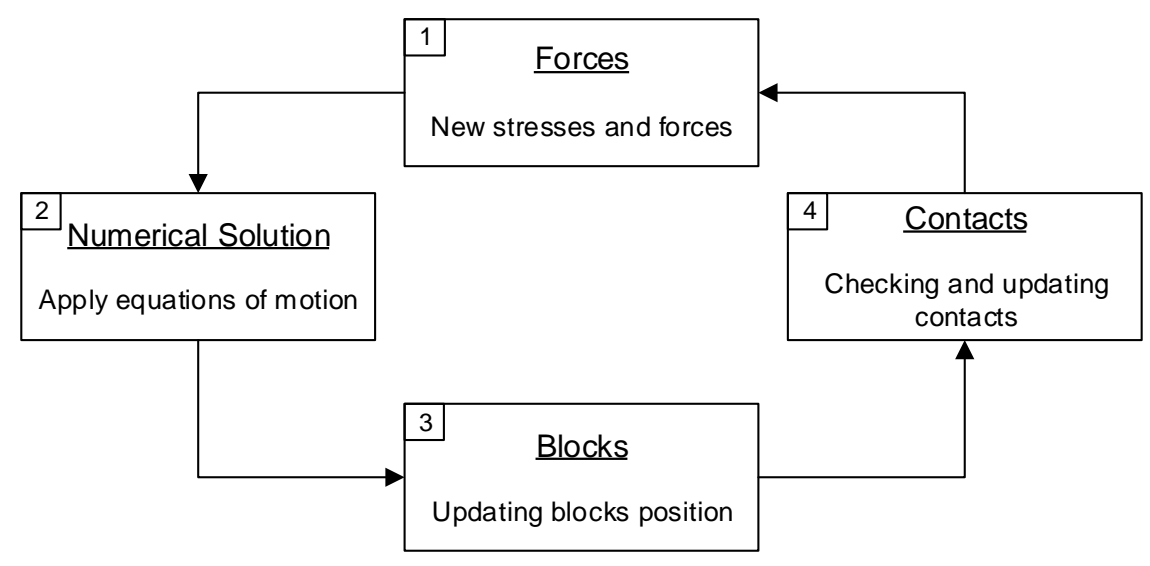

Fig. 2-Calculation cycle of the developed DEM tool 


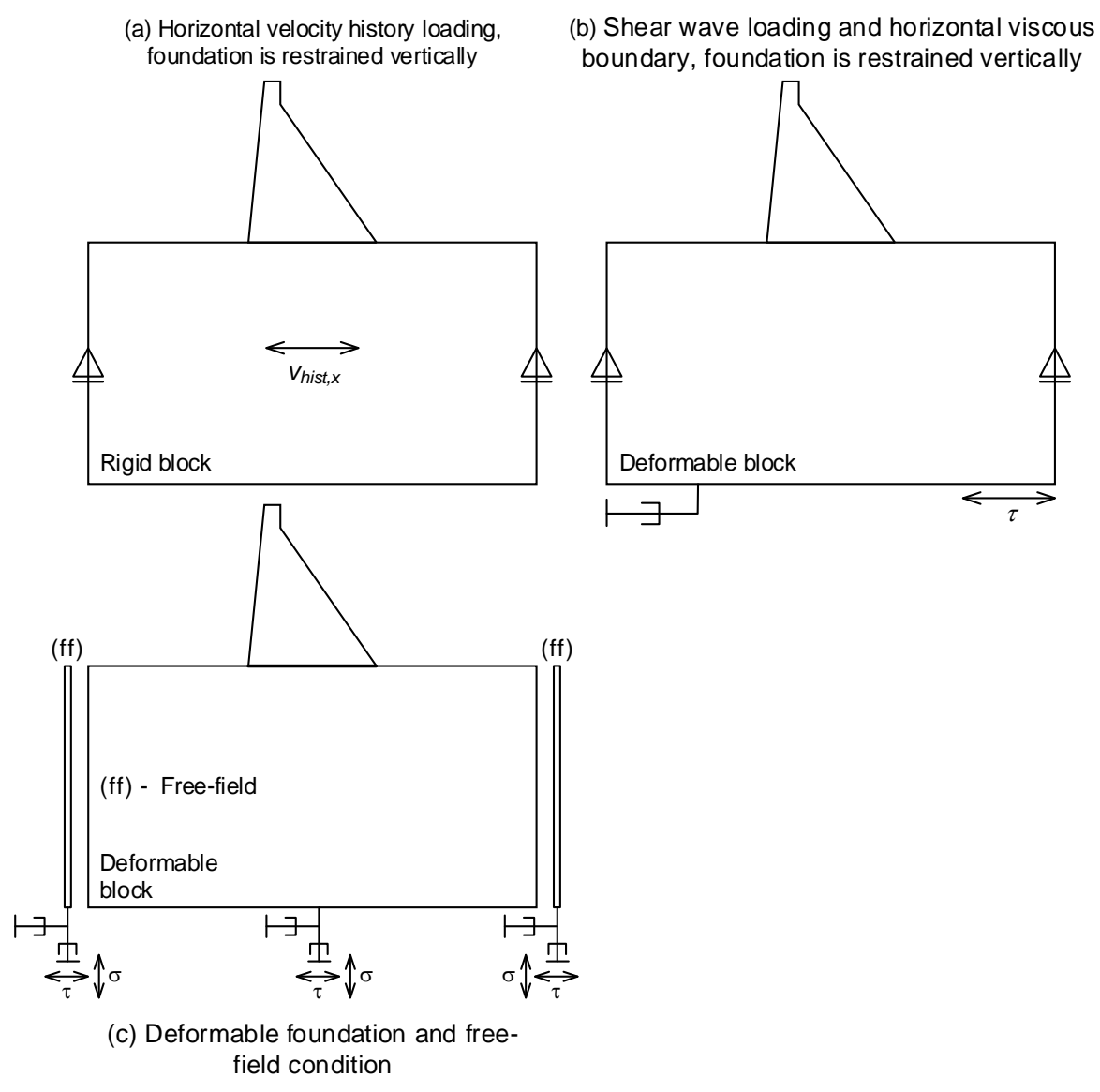

Fig. 3 - Model with (a) rigid foundation and application of the dynamic load using a velocity history; model with (b) deformable foundation and application of the dynamic load using a stress history; and model with (c) deformable foundation and application of the dynamic load using the free-field condition 


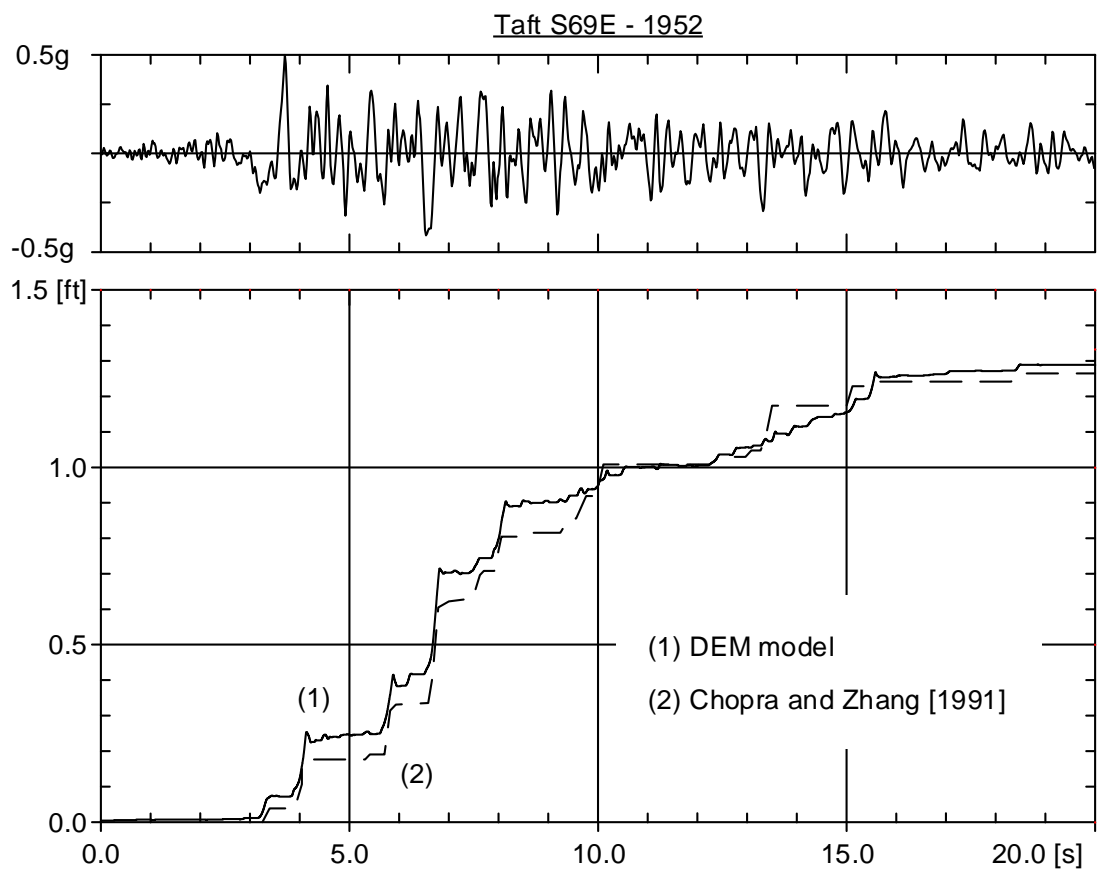

Fig. 4 - Sliding displacement of a gravity dam due to Taft S69E ground motion from the Chopra and Zhang model [1991] and from the DEM model 


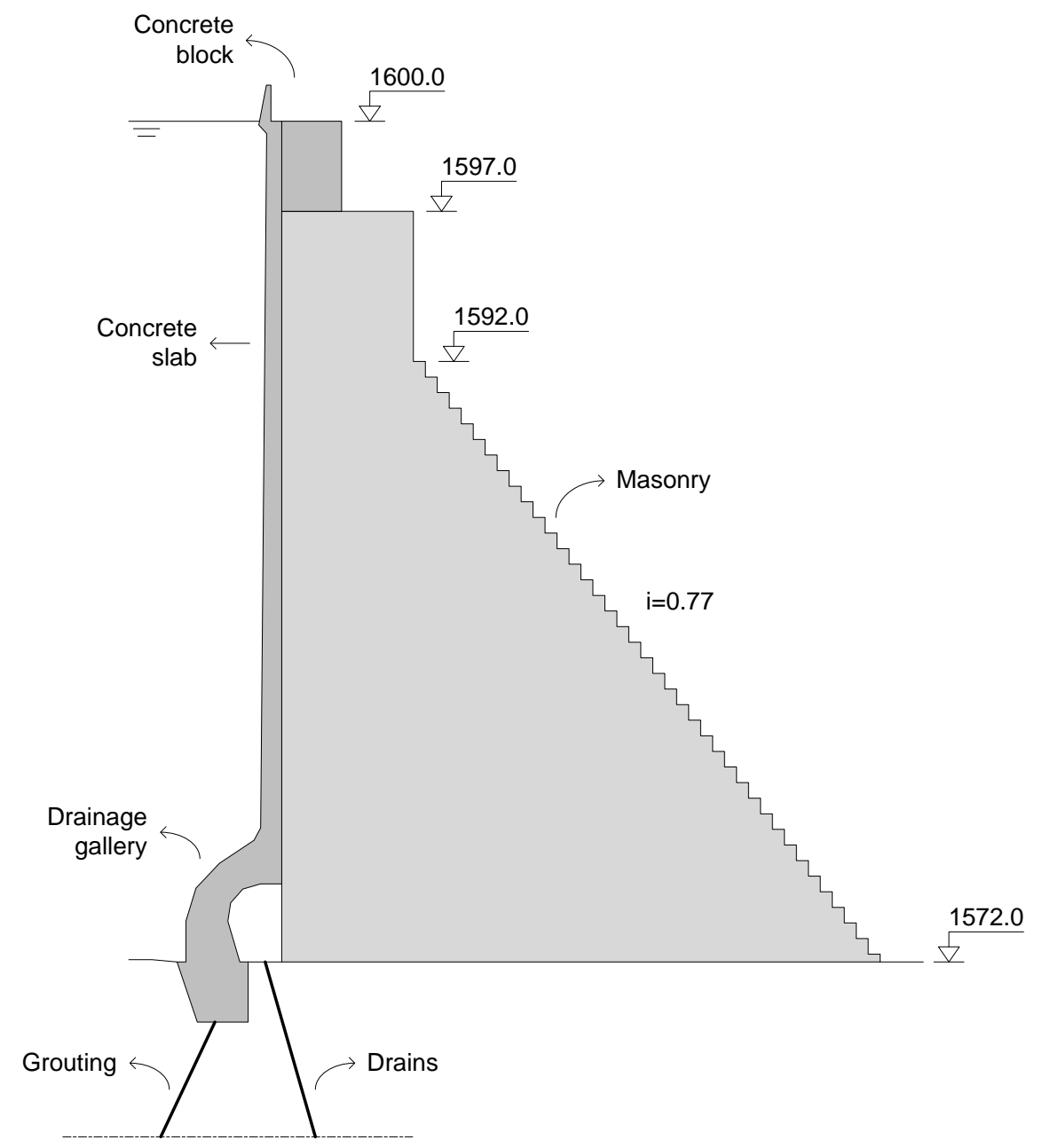

Fig. 5 - Lagoa Comprida main section after the rehabilitation works carried out between 1964 and 1967 [elevations in $\mathrm{m}$ ] 


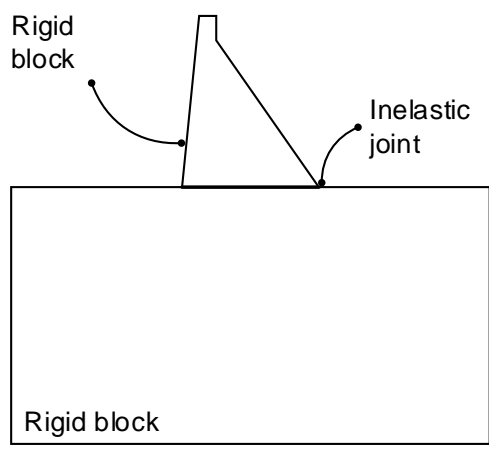

(a) Model R-R

(Rigid dam, Rigid foundation)

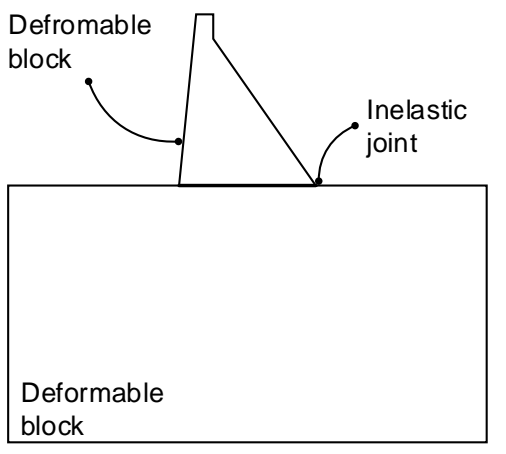

(c) Model D-D

(Deformable dam, Deformable foundation)

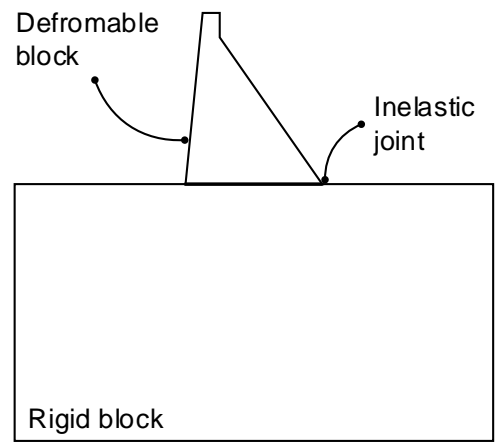

(b) Model D-R

(Deformable dam, Rigid foundation)

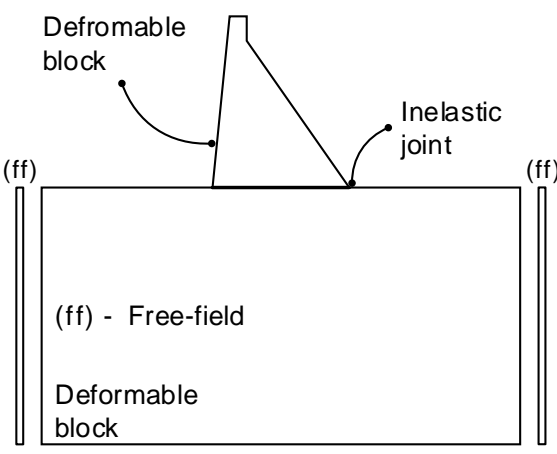

(d) Model F-F

(Free-field)

Fig. 6 - Main characteristics and designation of the numerical models 


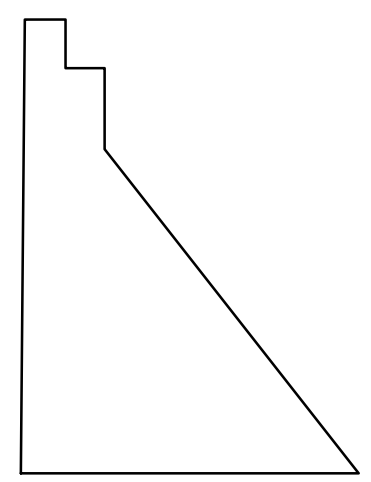

(a) Model R-R

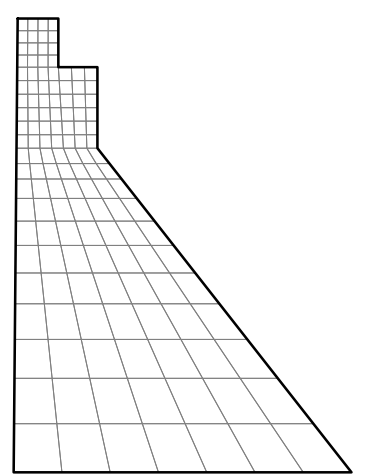

(b) Model D-R, Model D-D and Model F-F-1

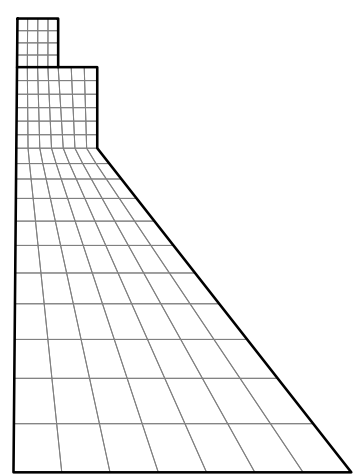

(c) Model F-F-2

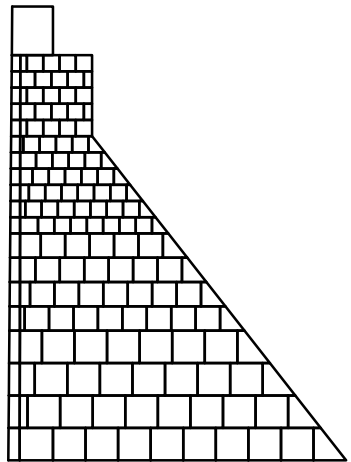

(d) Model F-F-3

Fig. 7 - Dam mesh discretization of the continuous and discontinuous models 


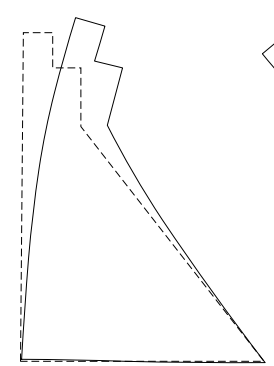

$f_{1}=5.7 \mathrm{~Hz}$

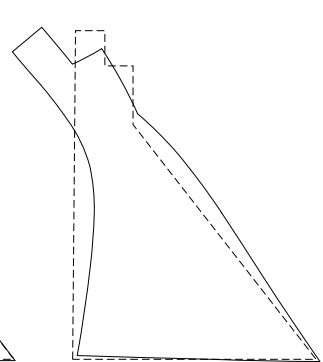

$\mathrm{f}_{2}=13.3 \mathrm{~Hz}$

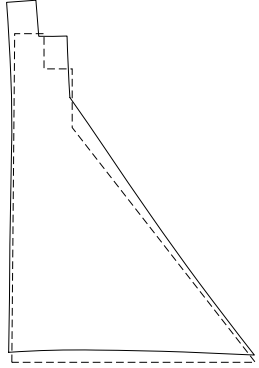

$f_{3}=18.9 \mathrm{~Hz}$

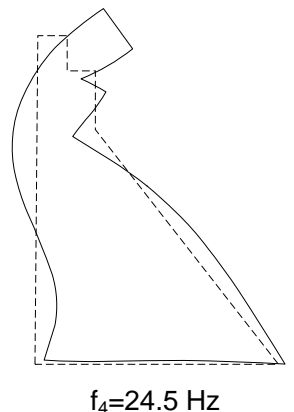

$\mathrm{f}_{4}=24.5 \mathrm{~Hz}$

Fig. 8 - Eigenmodes and eigenfrequencies 

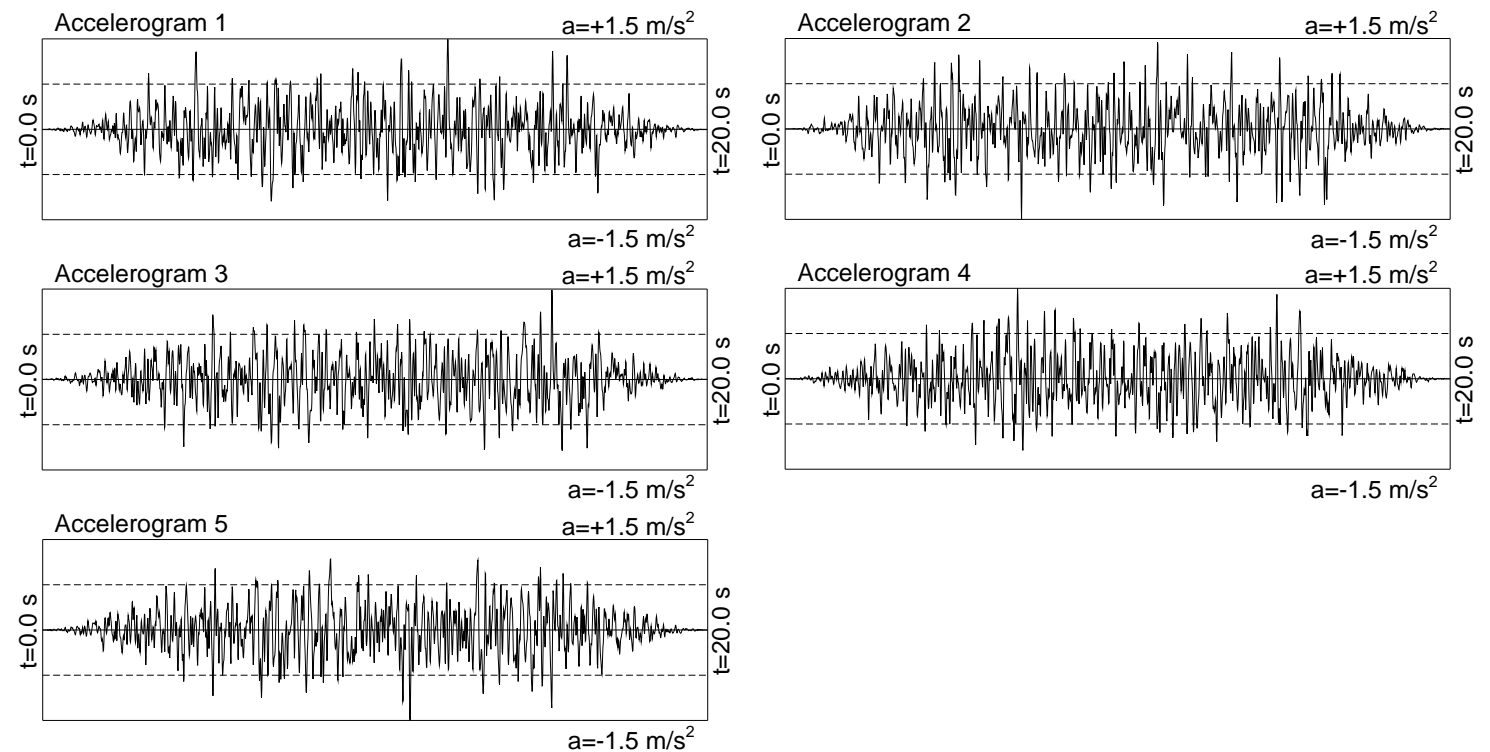

Fig. 9 - Accelerograms with peak acceleration of $1.5 \mathrm{~m} / \mathrm{s}^{2}$ 


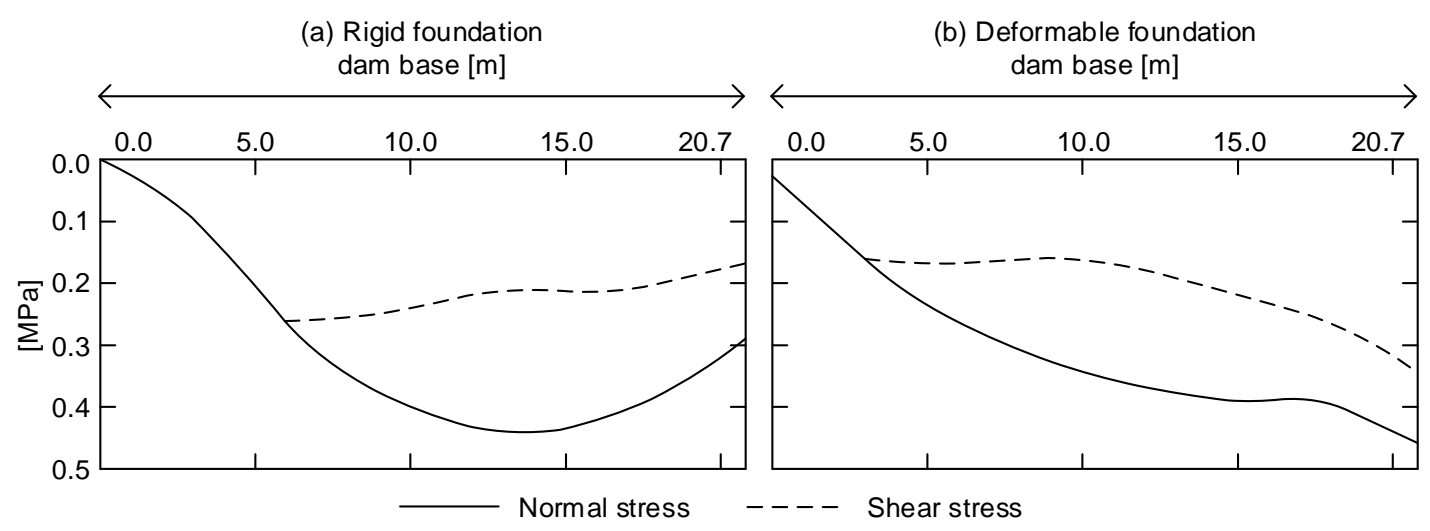

Fig. 10 - Stress on the base of the dam, for dead-loads, i.e. self-weight, hydrostatic pressure and uplift, (a) considering a rigid foundation (model D-R-1), and (b) a deformable foundation (model D-D-1) 


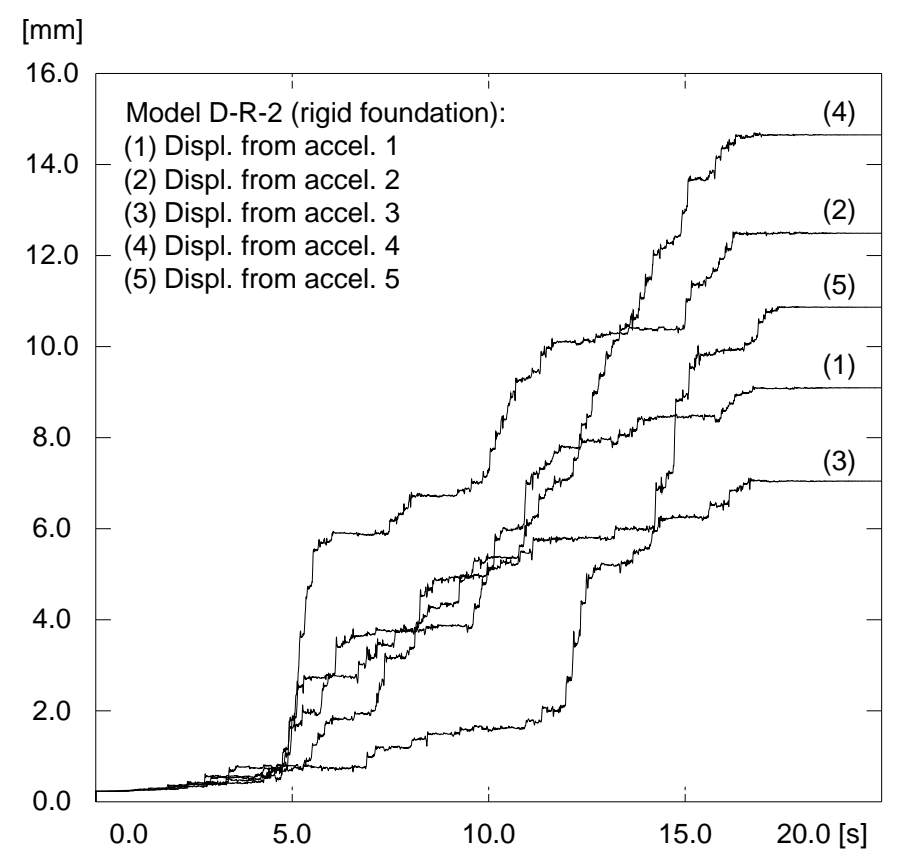

Fig. 11 - Permanent displacement history of the dam along the dam-foundation interface considering accelerograms 1 to 5, for the model with rigid foundation (model D-R-2) 


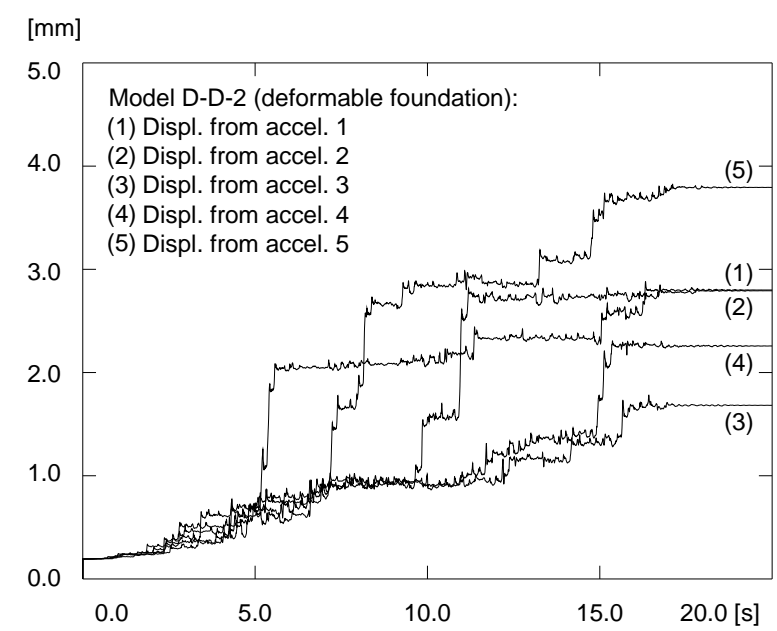

(a)

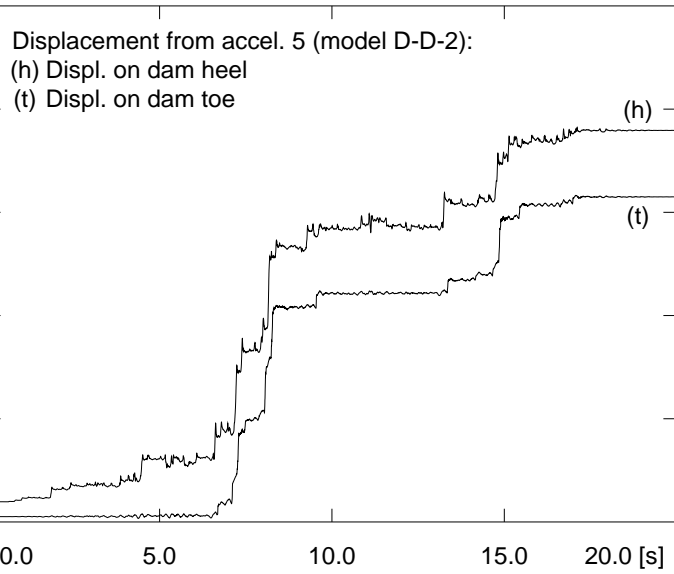

(b)

Fig. 12 - Permanent sliding history of the dam along the dam-foundation interface, for the model with deformable foundation (model D-D-2), (a) considering accelerograms 1 to 5; and (b) permanent displacement history measured at the heel and at the toe of the dam, for accelerogram 


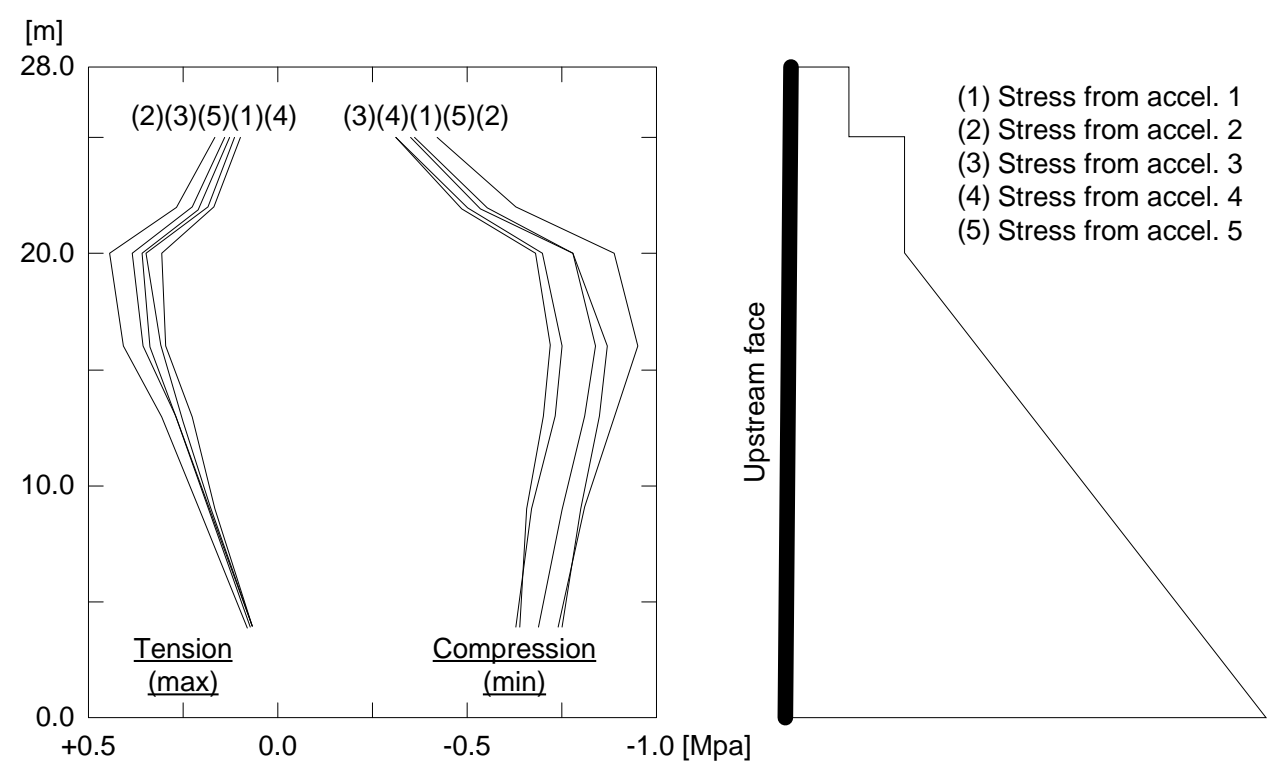

Fig. 13 - Vertical stress, minimum and maximum peak values, on the upstream face (model DD-3) 


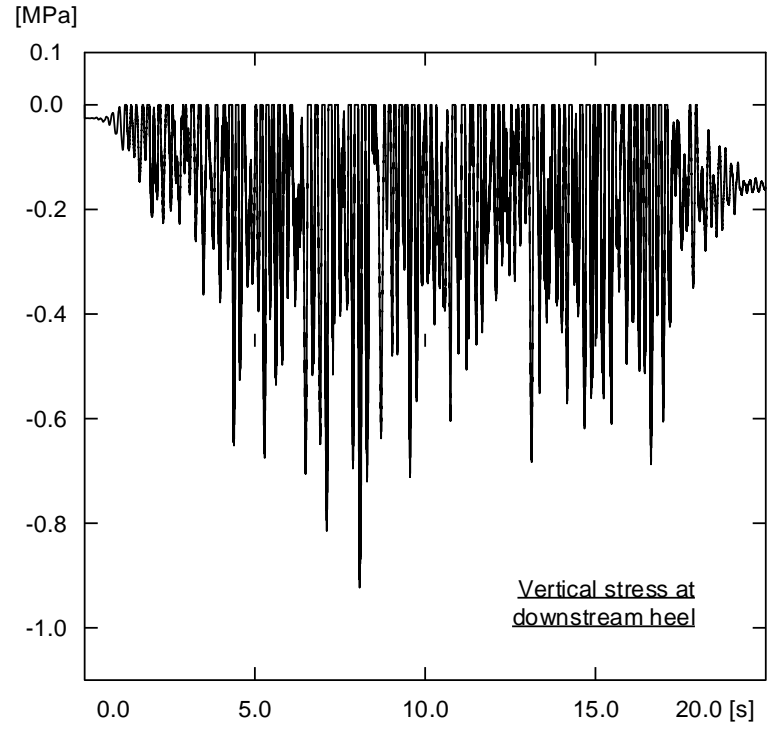

(a)

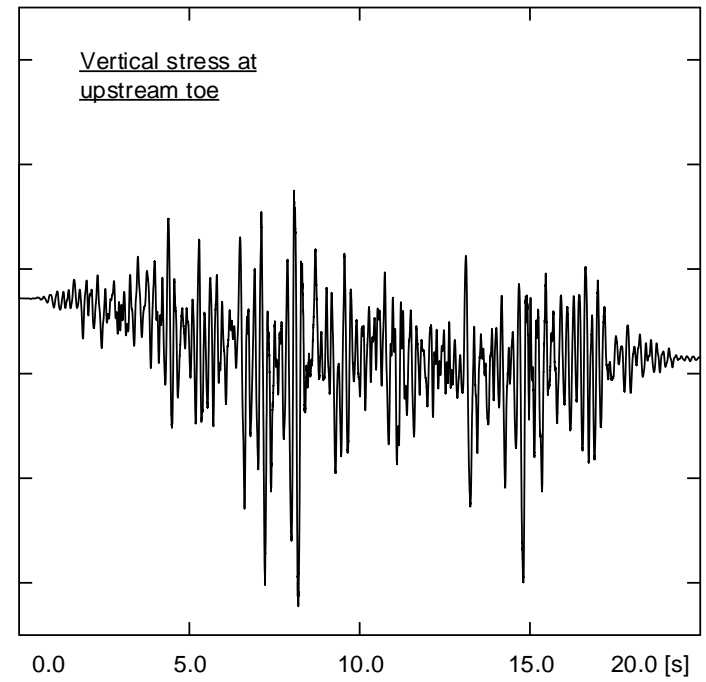

(b)

Fig. 14 - Vertical stress history on the dam heel (a), and on the dam toe (b) (model D-D-4) 


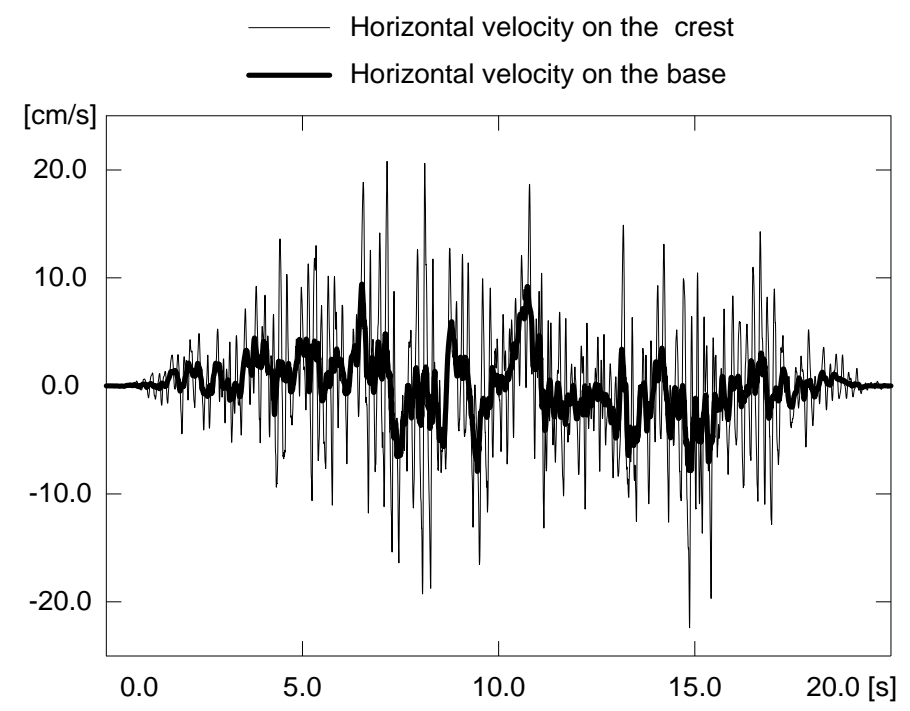

Fig. 15 - Horizontal velocity history at the base and at the crest of the dam (model D-D-5) 


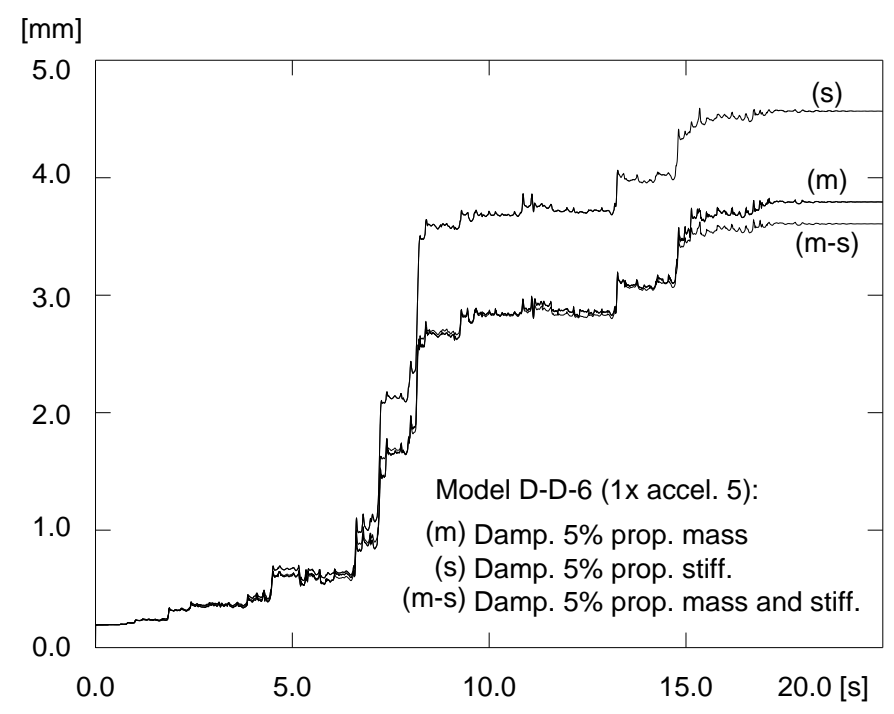

Fig. 16 - Sliding displacement history of the dam along the dam-foundation interface for different damping conditions (model D-D-6) 


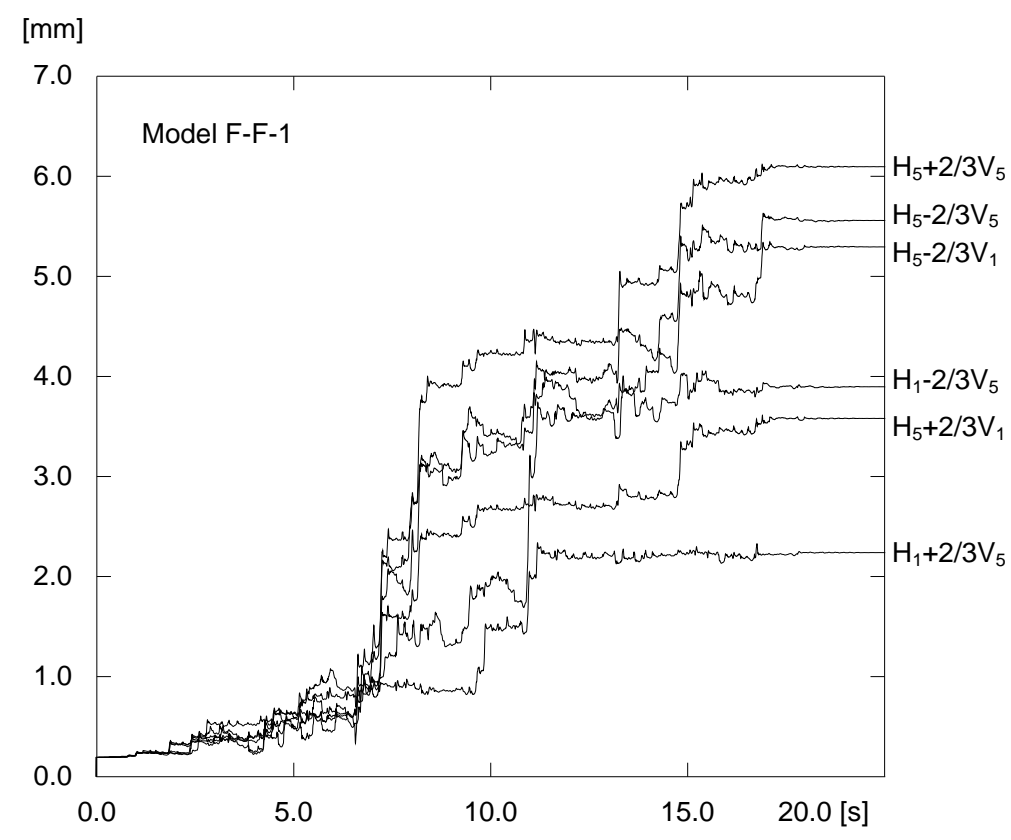

Fig. 17 - Sliding history of the dam along the dam-foundation interface with free-field condition (model F-F-1) 


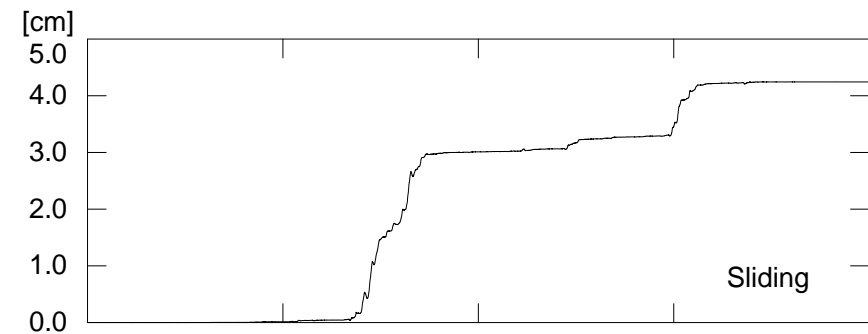

(a)

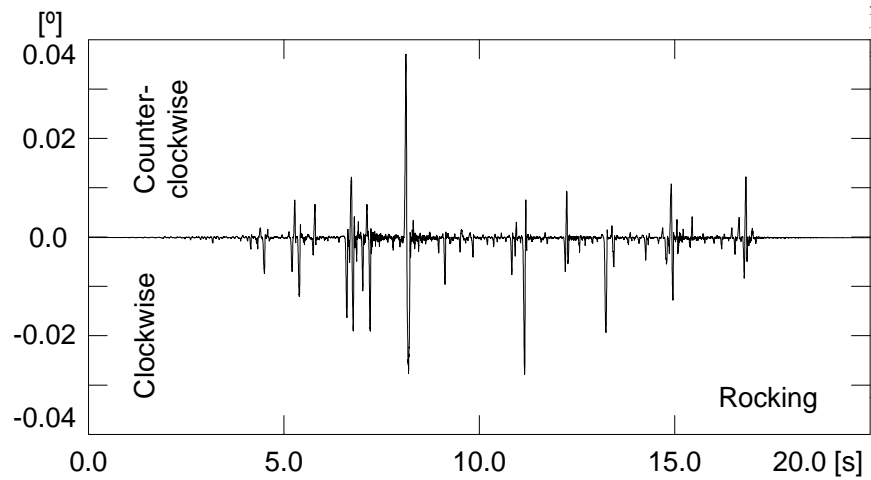

(b)

Fig. 18 - Sliding history (a) and rocking (b) of the concrete block located on the crest of the dam (model F-F-2) 


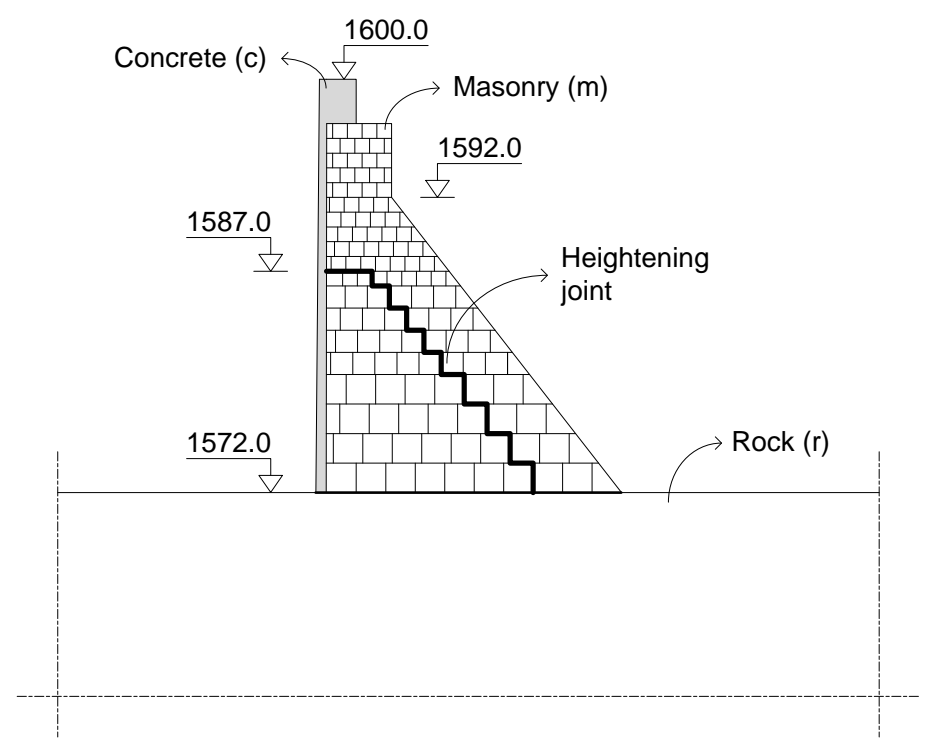

Fig. 19 - Detailed model of the dam with masonry discretization (model F-F-3) 

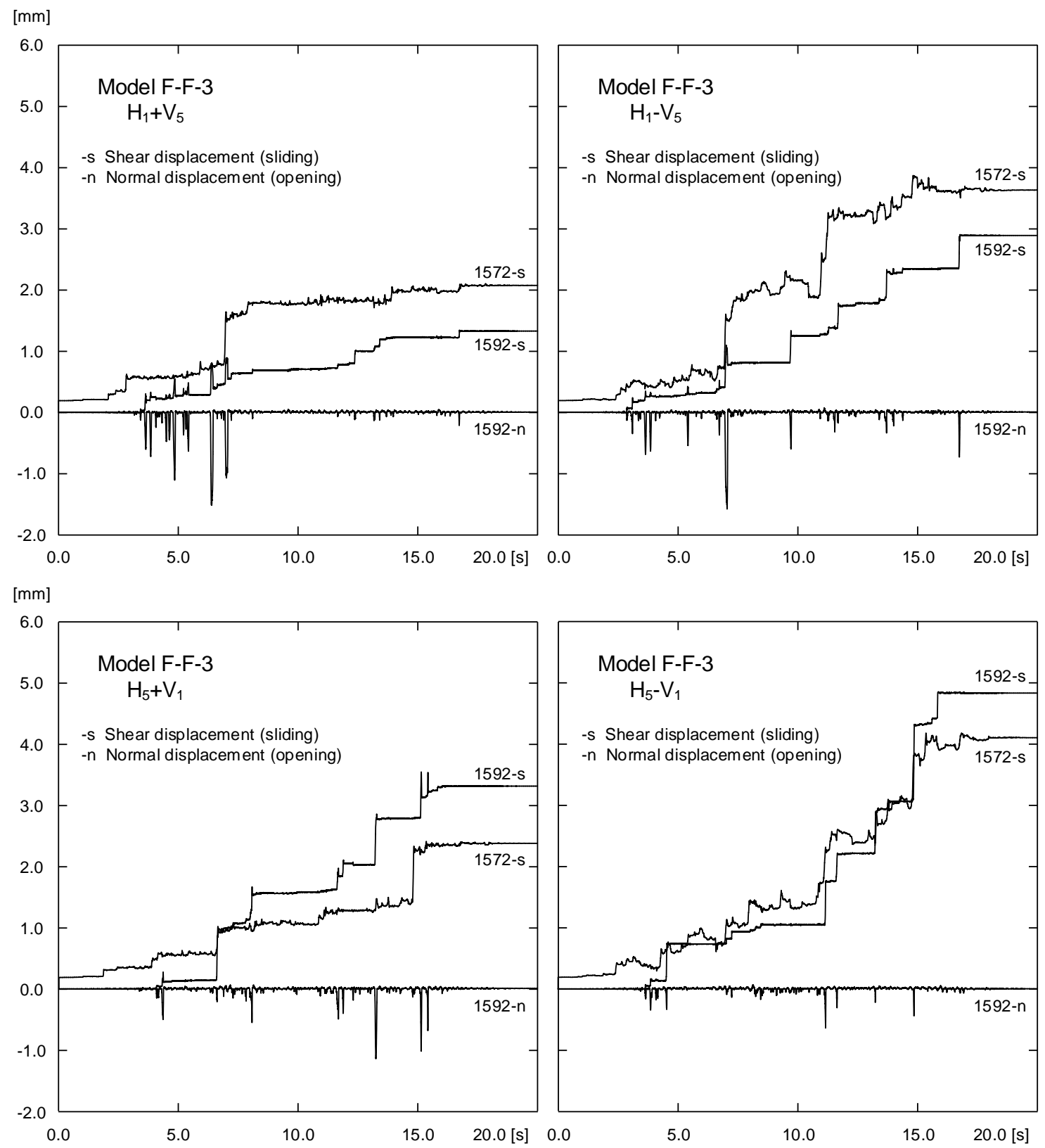

Fig. 20 - Displacements observed on the base of the dam (elev. 1572m) and on a superior section below the crest (elev. 1592m) (model F-F-3) 


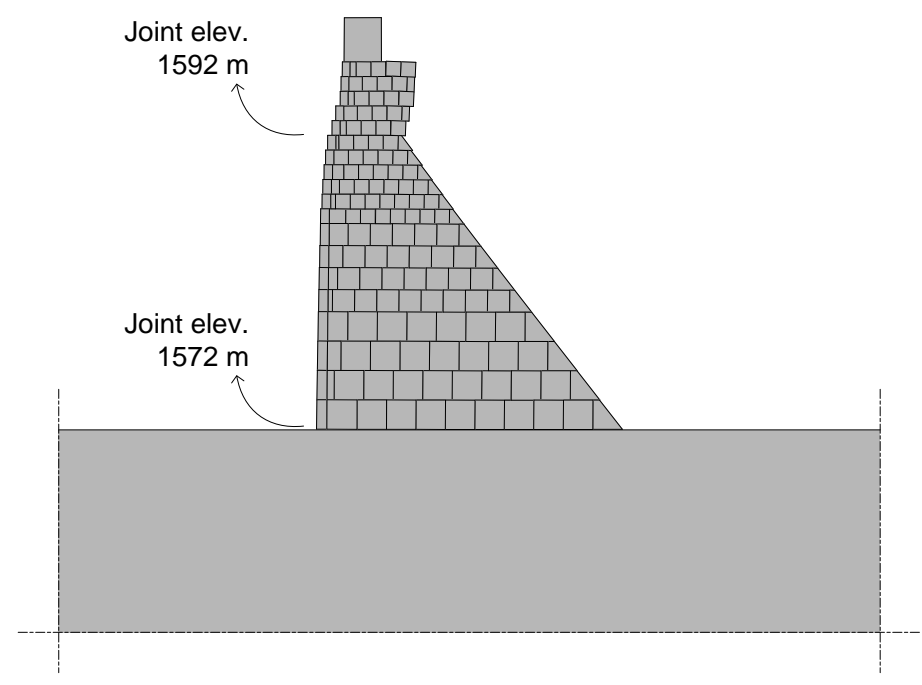

Fig. 21 - Cracks and permanent displacements resulting from the application of the earthquake (model F-F-3) 
Table 1 - Description of the seismic analyses

\begin{tabular}{|c|c|c|c|}
\hline Model & Analysis & $\begin{array}{l}\text { Rayleigh } \\
\text { damping }\end{array}$ & Seismic load \\
\hline Model R-R & (1) Permanent displacement & Mass & Horizontal \\
\hline Model D-R & $\begin{array}{l}\text { (1) Stress on the interface (static) } \\
\text { (2) Permanent displacement }\end{array}$ & Mass & Horizontal \\
\hline Model D-D & $\begin{array}{l}\text { (1) Stress on the interface (static) } \\
\text { (2) Permanent displacement } \\
\text { (3) Stress on the upstream face } \\
\text { (4) Stress on the interface (dynamic) } \\
\text { (5) Amplification effect of the seismic load } \\
\text { (6) Permanent displacement (varying damping) }\end{array}$ & $\begin{array}{l}\text { Mass } \\
\text { Mass } \\
\text { Mass } \\
\text { Mass } \\
\text { Var. }\end{array}$ & $\begin{array}{l}\text { Horizontal } \\
\text { Horizontal } \\
\text { Horizontal } \\
\text { Horizontal } \\
\text { Horizontal }\end{array}$ \\
\hline Model F-F & $\begin{array}{l}\text { (1) Permanent displacement } \\
\text { (2) Rocking of the concrete block on the crest } \\
\text { (3) Discontinuous model of the dam body }\end{array}$ & $\begin{array}{l}\text { Mass } \\
\text { Mass } \\
\text { Mass }\end{array}$ & $\begin{array}{l}\text { Hor. and ver. } \\
\text { Hor. and ver. } \\
\text { Hor. and ver. }\end{array}$ \\
\hline
\end{tabular}


Table 2 - Time step and damping coefficients

\begin{tabular}{|l|c|c|c|c|}
\hline \multicolumn{1}{|c|}{ Damping type } & $\Delta t[\mathrm{~s}]$ & $\begin{array}{c}\text { N. of steps } \\
\text { (Earthquake duration: } 20 \mathrm{~s})\end{array}$ & $\begin{array}{c}\alpha \\
{[1 / \mathrm{s}]}\end{array}$ & $\beta[\mathrm{s}]$ \\
\hline Proportional to the mass & $1.413 \mathrm{e}-4$ & 141543 & 3.770 & - \\
\hline Proportional to the stiffness & $3.760 \mathrm{e}-6$ & 5319149 & - & $2.653 \mathrm{e}-3$ \\
\hline Proportional to the mass and stiffness & $7.500 \mathrm{e}-6$ & 2666667 & 1.885 & $1.326 \mathrm{e}-3$ \\
\hline
\end{tabular}

